University of Wollongong

Research Online

Australian Institute for Innovative Materials -

Papers

Australian Institute for Innovative Materials

$1-1-2013$

Cation exchange at semiconducting oxide surfaces: Origin of light-induced performance increases in porphyrin dye-sensitized solar cells

Matthew J. Griffith

University of Wollongong, mjg48@uow.edu.au

Kenji Sunahara

Shinshu University

Akihiro Furube

Shinshu University

Attila J. Mozer

University of Wollongong, attila@uow.edu.au

David L. Officer

University of Wollongong, davido@uow.edu.au

See next page for additional authors

Follow this and additional works at: https://ro.uow.edu.au/aiimpapers

Part of the Engineering Commons, and the Physical Sciences and Mathematics Commons

Research Online is the open access institutional repository for the University of Wollongong. For further information contact the UOW Library: research-pubs@uow.edu.au 


\title{
Cation exchange at semiconducting oxide surfaces: Origin of light-induced performance increases in porphyrin dye-sensitized solar cells
}

\begin{abstract}
The origin of simultaneous improvements in the short-circuit current density (Jsc) and open-circuit voltage (Voc) of porphyrin dye-sensitized $\mathrm{TiO} 2$ solar cells following white light illumination was studied by systematic variation of several different device parameters. Reduction of the dye surface loading resulted in greater relative performance enhancements, suggesting open space at the TiO2 surface expedites the process. Variation of the electrolyte composition and subsequent analysis of the conduction band potential shifts suggested that a light-induced replacement of surface-adsorbed lithium (Li+) ions with dimethylpropylimidazolium (DMPIm+) ions was responsible for an increased electron lifetime by decreasing the recombination with the redox mediator. Variation of the solvent viscosity was found to affect the illumination time required to generate increased performance, while similar performance enhancements were not replicated by application of negative bias under dark conditions, indicating the light exposure effect was initiated by formation of dye cation molecules following photoexcitation. The substituents and linker group on the porphyrin chromophore were both varied, with light exposure producing increased electron lifetime and Voc for all dyes; however, increased Jsc values were only measured for dyes containing binding moieties with multiple carboxylic acids. It was proposed that the initial injection limitation and/or fast recombination process in these dyes arises from the presence of lithium at the surface, and the improved injection and/or retardation of fast recombination after light exposure is caused by the Li+ removal by cation exchange under illumination.
\end{abstract}

\section{Keywords}

origin, light, induced, performance, increases, porphyrin, dye, sensitized, solar, cells, oxide, surfaces, semiconducting, exchange, cation

\section{Disciplines}

Engineering | Physical Sciences and Mathematics

\section{Publication Details}

Griffith, M. J., Sunahara, K., Furube, A., Mozer, A. J., Officer, D. L., Wagner, P. W., Wallace, G. G. \& Mori, S. (2013). Cation exchange at semiconducting oxide surfaces: Origin of light-induced performance increases in porphyrin dye-sensitized solar cells. The Journal of Physical Chemistry C: Energy Conversion and Storage, Optical and Electronic Devices, Interfaces, Nanomaterials, and Hard Matter, 117 (23), 11885-11898.

\section{Authors}

Matthew J. Griffith, Kenji Sunahara, Akihiro Furube, Attila J. Mozer, David L. Officer, Pawel Wagner, Gordon G. Wallace, and Shogo Mori 


\title{
Cation Exchange at Semiconducting Oxide Surfaces: The Origin of Light-
}

\section{Induced Performance Increases in Porphyrin Dye-Sensitized Solar Cells}

\author{
Matthew J. Griffith, ${ }^{\dagger}{ }^{\ddagger}{ }^{*}$ Kenji Sunahara, ${ }^{\S}$ Akihiro Furube, ${ }^{\S}$ Attila J. Mozer, ${ }^{\dagger}$ David L. Officer, ${ }^{\dagger}$ Pawel \\ Wagner, $^{\dagger}$ Gordon G. Wallace ${ }^{\dagger}$ and Shogo Mori ${ }^{\ddagger, *}$
}

ARC Centre of Excellence for Electromaterials Science and Intelligent Polymer Research Institute, Innovation Campus, University of Wollongong, Northfields Avenue, Wollongong, NSW, 2522, Australia

National Institute of Advanced Industrial Science and Technology (AIST), Tsukuba Central 5, Tsukuba, Ibaraki, 305-8565, Japan.

Division of Chemistry and Materials, Faculty of Textile Science and Technology, Shinshu University, Ueda, Nagano, 386-8567, Japan.

\section{RECEIVED DATE}

\section{CORRESPONDING AUTHOR FOOTNOTE}

Dr M. Griffith: Faculty of Textile Science and Technology, Shinshu University, Ueda, Nagano, 3868567, Japan. Telephone: +81 (0)80 4373 3028. Email: mjg48@uow.edu.au

Associate Professor S. Mori: Faculty of Textile Science and Technology, Shinshu University, Ueda, Nagano, 386-8567, Japan. Telephone:+81 (0)268 215 818. Email: shogmori@shinshu-u.ac.jp

\footnotetext{
${ }^{\dagger}$ ARC Centre of Excellence for Electromaterials Science, University of Wollongong

$\S_{\text {National Institute of Advanced Industrial Science and Technology (AIST) }}$

${ }^{\ddagger}$ Faculty of Textile Science and Technology, Shinshu University
} 


\section{ABSTRACT}

The origin of simultaneous improvements in the short circuit current density $\left(J_{\mathrm{sc}}\right)$ and open circuit voltage $\left(V_{\text {oc }}\right.$ ) of porphyrin dye-sensitized $\mathrm{TiO}_{2}$ solar cells following white light illumination was studied by systematic variation of several different device parameters. Reduction of the dye surface loading resulted in greater relative performance enhancements, suggesting open space at the $\mathrm{TiO}_{2}$ surface expedites the process. Variation of the electrolyte composition and subsequent analysis of the conduction band potential shifts suggested that a light-induced replacement of surface-adsorbed lithium $\left(\mathrm{Li}^{+}\right)$ions with dimethylpropylimidazolium $\left(\mathrm{DMPIm}^{+}\right)$ions was responsible for an increased electron lifetime by decreasing the recombination with the redox mediator. Variation of the solvent viscosity was found to effect the illumination time required to generate increased performance, whilst similar performance enhancements were not replicated by application of negative bias under dark conditions, indicating the light exposure effect was initiated by formation of dye cation molecules following photoexcitation. The substituents and linker group on the porphyrin chromophore were both varied, with light exposure producing increased electron lifetime and $V_{\text {oc }}$ for all dyes, however, increased $J_{\text {sc }}$ values were only measured for dyes containing binding moieties with multiple carboxylic acids. It was proposed that there an initial injection limitation and/or fast recombination process in these dyes arises from the presence of lithium at the surface, and the improved injection and/or retardation of fast recombination after light exposure was caused by the $\mathrm{Li}^{+}$removal by cation exchange under illumination .

KEYWORDS: porphyrin, dye sensitized solar cells, ion exchange, injection yield, light exposure 


\section{INTRODUCTION}

Over the last two decades dye-sensitized solar cells (DSSCs) have emerged as an innovative technology for the development of low cost, renewable and environmentally acceptable energy production. ${ }^{1-3}$ Efficient charge separation in these devices is achieved by photoinduced electron injection from a sensitizing dye into the conduction band of a metal oxide electrode to which it is chemically anchored. The resulting dye cations are subsequently reduced by a redox electrolyte, which also conducts holes to the cathode. The solar-to-electric power conversion efficiencies of DSSCs depend on a balance of the kinetics for charge injection, collection, recombination and dye regeneration processes, ${ }^{4}$ with the best devices currently exhibiting power conversion efficiencies of 11-12 \% under AM 1.5 illumination.-8

The efficient light harvesting potential of porphyrins, exemplified by their primary role in photosynthesis, makes them promising candidates for photosensitizers within DSSCs. ${ }^{79}$ Their synthesis is relatively straightforward, and their optical and electronic properties can be easily tuned via chemical modification of the porphyrin core, ${ }^{10}$ the number of porphyrin units, ${ }^{11,12}$ and the linker between the core and the inorganic oxide. ${ }^{13}$ The capability of porphyrin sensitizers was recently highlighted by a report demonstrating a new DSSC benchmark efficiency of $12.3 \%$ under AM 1.5 full sunlight for a device with a donor- $\pi$-acceptor zinc porphyrin sensitizer coupled with a cobalt-based redox mediator. ${ }^{7}$ This report demonstrated the remarkable potential of this class of chromophores, although the majority of porphyrin dyes have not approached such impressive efficiencies despite major progress in the development of innovative design strategies. ${ }^{14-17}$ It is therefore clearly important that the factors that affect the performance of the porphyrin dyes as sensitizers are systematically elucidated and understood. The most notable limitations for a number of porphyrin dyes include restricted electron injection yields and an enhanced recombination between injected electrons and the acceptor species in the $\mathrm{I}^{-} / \mathrm{I}_{3}{ }^{-}$redox mediator. ${ }^{10,18-20}$ Strategies to remove such limitations have driven the development of several new 
porphyrin dyes, ${ }^{21-24}$ however, despite encouraging progress, the reasons for limitations in porphyrin sensitizer performance are not completely understood.

The exposure of DSSCs to light for various time periods has been shown to produce several interesting effects, including performance enhancements and recovery after thermal aging. ${ }^{25,26}$ This phenomenon is of great interest due to its considerable practical implications, however, the origin remains ambiguous. Indeed, the behaviour of DSSCs in response to light exposure for time periods ranging from 1 hour to several days is highly dye-dependent. Previous reports have proposed a range of explanations, including enhanced electron transport arising from the creation of shallow $\mathrm{TiO}_{2}$ electronic states for a ruthenium polypyridyl dye, ${ }^{26}$ a positive conduction band shift and photo-production of surface states in the $\mathrm{TiO}_{2}$ for a perylene dye, ${ }^{27}$ or a rearrangement of the dye molecules under illumination for a dendritic oligothiophene ruthenium sensitiser. ${ }^{28}$ Recently, a detailed study of this process using time-resolved luminescence on DSSCs prepared with ruthenium complex dyes and various electrolytes determined that the improved $J_{\mathrm{sc}}$ observed after light exposure can be attributed to an increased injection yield arising from a change in the kinetics of injection caused by a positive conduction band shift. ${ }^{29}$ This paper also reported a reduction in the charge recombination after light exposure to mitigate voltage losses from the conduction band shift. For DSSCs prepared from a zinc porphyrin dye we previously reported that a short light exposure treatment produced simultaneous improvements in the $J_{\mathrm{sc}}, V_{\mathrm{oc}}$ and fill factor for a zinc porphyrin DSSC. This result could not be completely explained by any of the mechanisms previously reported. ${ }^{25}$ Understanding the relationship between dye structure and such effects is essential to design sensitizers for highly efficient DSSCs.

In this report, we investigate the origin of simultaneous improvements, following light exposure, in all photovoltaic performance parameters that we recently reported for porphyrin-sensitized solar cells. Experiments performed to systematically examine the effect of light exposure on the $\mathrm{TiO}_{2}$ conduction band potential and electron lifetime as a function of (i) dye loading, (ii) electrolyte composition, (iii) 
solvent viscosity, and (iv) dye structure, have provided much clearer insight into the principal mechanism responsible for the performance improvements.

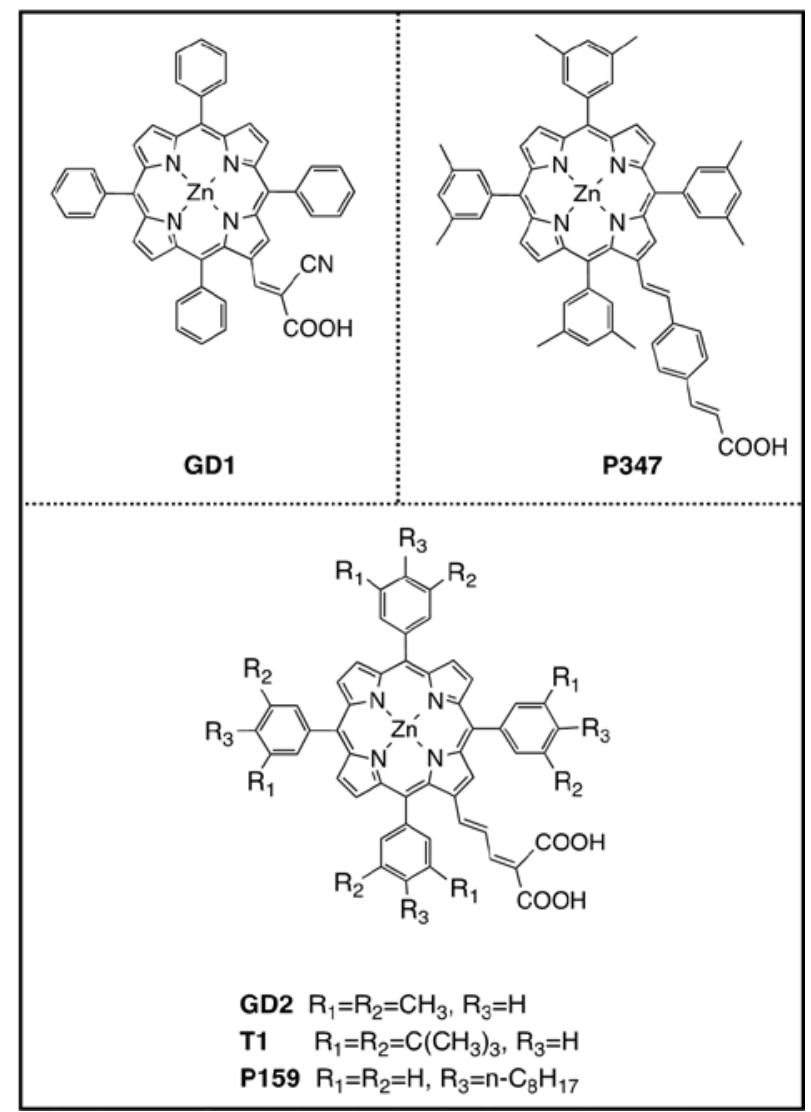

Figure 1. Structures of porphyrin dyes used in this study.

\section{EXPERIMENTAL}

Materials. The porphyrin dyes studied here included GD1 [5,10,15,20-tetraphenyl-2-(2-carboxy-2cyanoethenyl)porphyrinato zinc (II)], GD2 [5,10,15,20-tetra(3,5-dimethylphenyl)-2-(4,4-dicarboxybuta1,3-dienyl)porphyrinato zinc (II)], P159 [5,10,15,20-tetra(4-n-octylphenyl)-2-(4,4-dicarboxybuta-1,3dienyl)porphyrinato zinc (II)], T1 [5,10,15,20-tetra(3,5-di-tert-butylphenyl)-2-(4,4-dicarboxybuta-1,3dienyl)porphyrinato zinc (II)] and P347 [5,10,15,20-tetra(3,5-dimethylphenyl)-2-(p-(2carboxyethenyl)styryl)porphyrinato zinc (II)]. The chemical structures of these dyes are displayed in Figure 1. Dye molecules GD1, GD2 and $\boldsymbol{P 1 5 9}$ were prepared as previously reported. ${ }^{11,30,31}$ The synthesis of porphyrin dyes $\boldsymbol{P} 347$ and $\mathbf{T 1}$ will be reported separately. 
DSC Fabrication. $\mathrm{TiO}_{2}$ films were prepared on fluorine-doped tin oxide (FTO) substrates (Asahi Glass Co., Asahi-U, $\mathrm{R}_{\mathrm{s}} \leq 12 \Omega \mathrm{sq}^{-1}$ ) using a doctor-blade technique and were sintered at $550^{\circ} \mathrm{C}$ for 30 minutes in air. The FTO-glass substrates were sonicated in propanol and exposed to UV light and ozone for 15 minutes prior to $\mathrm{TiO}_{2}$ paste deposition. DSSCs were prepared using a $2.5 \mu \mathrm{m}$ transparent $\mathrm{TiO}_{2}$ layer (Nanoxide-T, Solaronix), with film thicknesses measured using a Dektak 150 profilometer. Each film was briefly reheated to $450{ }^{\circ} \mathrm{C}$ before immersion into $0.2 \mathrm{mM}$ anhydrous tetrahydrofuran solutions of porphyrin dyes for 2 hours. Reduced dye loading samples were prepared by sensitization from diluted $0.02 \mathrm{mM}$ anhydrous tetrahydrofuran solutions of porphyrin dyes for 2 hours. Sandwich-type DSSCs were assembled using a $25 \mu \mathrm{m}$ Hymilan sealant and Pt-sputtered FTO-glass counter electrodes. Electrolyte solutions of varying composition were injected between the electrodes through a hole in the counter electrode, which was subsequently sealed with additional Hymilan. Electrolyte compositions employed in this study included:

I (Standard): 0.6 M 1,2-dimethyl-3-propylimidazolium (DMPImI), 0.5 M 4-tert-butylpyridine (tBP), 0.1 M LiI and 0.05 $\mathrm{M} \mathrm{I}_{2}$ in acetonitrile

II (DMPIm ${ }^{+}$rich): $0.7 \mathrm{M}$ DMPImI and $0.05 \mathrm{M} \mathrm{I}_{2}$ in acetonitrile

III ( $\mathrm{Li}^{+}$rich): $0.7 \mathrm{M} \mathrm{LiI}$ and $0.05 \mathrm{M} \mathrm{I}_{2}$ in acetonitrile

Light exposure. Light exposure treatments were performed by illumination of the DSSCs with a 100 mW cm ${ }^{-2}$ simulated AM 1.5 light source (YSS-100A, Yamashita Denso) identical to that used for performance characterisation. Light exposure was performed at open circuit for one hour. The temperature of the solar cells during this treatment was not controlled.

DSSC Characterization. Current-voltage curves were recorded using a Keithley 2400 source measure unit after illuminating the DSSCs with a simulated $100 \mathrm{~mW} \mathrm{~cm}^{-2}$ air mass AM 1.5 light source (YSS-100A, Yamashita Denso). The light intensity was adjusted using a calibrated silicon solar cell. The device area was masked with black paint defining an aperture slightly larger than the active area. ${ }^{32}$ The light intensity of the simulated sunlight source was reduced for specific measurements using neutral density filters. Incident photon-to-current conversion efficiency (IPCE) spectra were recorded on a set- 
up using the monochromated output from a xenon lamp equipped with sorting filters (SM-25, Bunkou, Keiki). The size of the output beam was larger than the DSSC active area. The short circuit current response of devices was recorded in $10 \mathrm{~nm}$ steps using a Keithley 2400 source measure unit referenced to the output of a calibrated silicon diode.

Electron Lifetime and Diffusion Coefficient Measurements. Electron lifetimes and diffusion coefficients were determined using stepped-light induced measurements of photocurrent and photovoltage (SLIM-PCV) transients. ${ }^{33}$ Measurements were performed using a $635 \mathrm{~nm}$ diode laser (Coherent, LabLaser) illuminating the entire DSSC active area. This wavelength was selected as the dyes are weakly absorbing at $635 \mathrm{~nm}$, allowing a relatively uniform generation of electron density throughout the entire $\mathrm{TiO}_{2}$ film thickness. The illumination intensity of the laser, controlled by the input voltage, produced values ranging from $1 \mathrm{~mW} \mathrm{~cm}^{-2}$ to $10 \mathrm{~mW} \mathrm{~cm}^{-2}$. Photocurrent and photovoltage transients were induced by the small stepwise $(\leq 10 \%)$ change of the laser intensity, controlled with a PC using a digital-to-analogue converter. Induced transients were measured by a fast multimeter (AD7461A, Advantest). Electron densities at each laser illumination intensity were determined by a charge extraction method in which the light source is switched off at the same time as the DSSC is switched from open to short circuit. ${ }^{34}$ The resulting current was integrated, with the electron density calculated from the amount of charge extracted. Diffusion coefficients were determined by fitting the current decays to a single exponential as previously reported, ${ }^{33}$ although we note that this treatment assumes no recombination losses during charge transport. Electron lifetimes were determined by fitting the voltage transients to single exponential decays as previously reported. ${ }^{33}$ The electron diffusion lengths of devices were calculated from transient measurements using a previously reported method where the electron lifetime and diffusion coefficient are determined at the same quasi-static Fermi level. ${ }^{35}$ For this purpose the electron lifetime $\left(\tau_{n}\right)$ was plotted against the electron density at open circuit and the diffusion coefficient $\left(D_{n}\right)$ was plotted against the electron density at short circuit for identical illumination levels. The short circuit electron density was determined using the previously mentioned charge extraction apparatus; however, no compensating bias was applied to the devices under 
illumination. After fitting both trends to power laws, the diffusion length, $L_{\mathrm{n}}$ was calculated as $\left(\tau_{n} D_{n}\right)^{1 / 2}$ for $\tau$ and $D$ values computed at the same electron density. The validity of this equation, which assumes a valid linearization of the charge recombination, was checked by determining the order of recombination using semi-logarithmic plots of open circuit voltage versus light intensity and electron lifetime versus open circuit voltage.

\section{RESULTS AND DISCUSSION}

\section{Dye Loading Variation}

GD2 porphyrin-sensitized solar cells were prepared using thin $(\sim 2.5 \mu \mathrm{m}) \mathrm{TiO}_{2}$ and their current voltage characteristics immediately recorded. DSSCs were then treated with a one hour light exposure (100 mW cm $\mathrm{m}^{-2}$ simulated AM 1.5 sunlight) at open circuit and the current - voltage characteristics were re-measured. These results are shown in Figure 2. Device photocurrents were limited compared to our previously reported values ${ }^{25,30}$ due to the use of thin $\mathrm{TiO}_{2}$ films without scattering layers employed in order to avoid possible recombination during charge extraction measurements performed on the same devices. The 1 hour light exposure led to a $6 \%$ increase in the $J_{s c}$ in conjunction with a simultaneous 5 \% increase in both the $V_{\text {oc }}$ and fill factor, resulting in a $16 \%$ enhancement of the power conversion efficiency. The magnitude of the efficiency enhancement upon light exposure is in close agreement with values we have previously reported for DSSCs prepared with this porphyrin dye. ${ }^{25}$ Our previous work on the light exposure effect indicated that heat treatment of devices in the dark produces only small performance improvements, while light treatment using a UV long-pass or IR short-pass filter induces similar improvements to the full simulated AM 1.5 spectrum, suggesting that the effect is linked to the photo-excitation of the porphyrin dye molecules. Accumulation of electrons in the $\mathrm{TiO}_{2}$ was considered as a possible mechanism for the light exposure effect since the treatment is performed under open circuit conditions where electron density accumulates due to zero extraction. However, accumulating charges by applying a negative bias to the $\mathrm{TiO}_{2}$ electrode in the dark did not reproduce the same photovoltaic 
improvements as the light exposure effects but rather produced the opposite trends in $V_{\mathrm{oc}}$ and $J_{\mathrm{sc}}$ (see SI, Figure S1). This result, coupled with our previous observations, suggests that photo-oxidation of the dye molecules plays a crucial role in the light exposure effect.

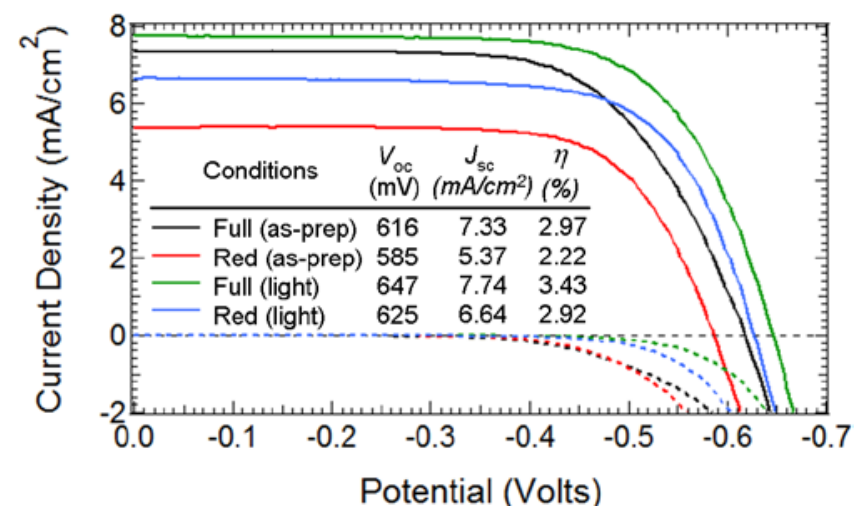

Figure 2. Current density-voltage $(J-V)$ curves for full and reduced dye loadings before and after light exposure for GD2 DSSCs. The dark $J-V$ curves are shown as dashed lines and the inset displays the photovoltaic performance parameters of each device.

To gain insight into the role of the dye molecule in the light exposure mechanism, the dye surface coverage was reduced by $\sim 50 \%$ by sensitizing films from diluted dye bath solutions. The reduced dye loading DSSCs were then subjected to the same $1 \mathrm{hr}$ light exposure treatment. Current - voltage curves and photovoltaic performance parameters for the reduced dye loadings are also included in Figure 2. Light exposure of the reduced dye devices produced a $J_{\text {sc }}$ enhancement of $24 \%$, a $6 \%$ increase in the $V_{\text {oc }}$ and an unchanged fill factor, leading to a $32 \%$ enhancement of the power conversion efficiency. The $V_{\text {oc }}$ increase is similar to that observed with full dye surface coverage (6 \%), however the lightinduced photocurrent enhancement is notably larger, leading to a larger relative increase in the initial device efficiency for the reduced dye device. This result implies that the ratio between the number of dye molecules and electrolyte species plays an important role in the light exposure performance enhancement mechanism.

The role of the dye molecules was examined further by measuring open circuit voltage and short circuit current decays for $\boldsymbol{G D 2}$-sensitized DSSCs with different dye coverages. Electron lifetimes and diffusion coefficients determined before and after 1 hour light exposure are shown for different laser intensities in 
Figure 3. The raw transients from which this data is derived are shown in Figures S2-S5 (Supporting Information). Photovoltage decay measurements demonstrate a factor of 2 to 4 increase in the electron lifetime $(\tau)$ at matched electron density for the full dye loading after light exposure (Figure 3(b)). Conversely, a decrease in the electron diffusion coefficient (D) at the same electron density was also observed as seen in Figure 3(a). The $V_{\text {oc }}$ vs electron density plot exhibits no shift in either the slope or intercept before and after light exposure (Figure 3(c)). Since each device employs an identical redox mediator, this lack of change indicates an identical $\mathrm{TiO}_{2}$ conduction band level and no change in the trap density or distribution before and after light exposure. The trends in electron lifetime and diffusion coefficients following light exposure are identical for the reduced and full dye loading devices. When the dye loading is reduced, the diffusion coefficients and conduction band potentials remain identical to the sample with full dye loading, however, the electron lifetime is slightly shorter for the reduced dye sample. This is indicative of a physical blocking effect, where decreasing the amount of dye diminishes the blocking effect, allowing $\mathrm{I}_{3}{ }^{-}$acceptor species closer to the $\mathrm{TiO}_{2}$ surface and reducing the electron lifetime through an enhanced probability for recombination.
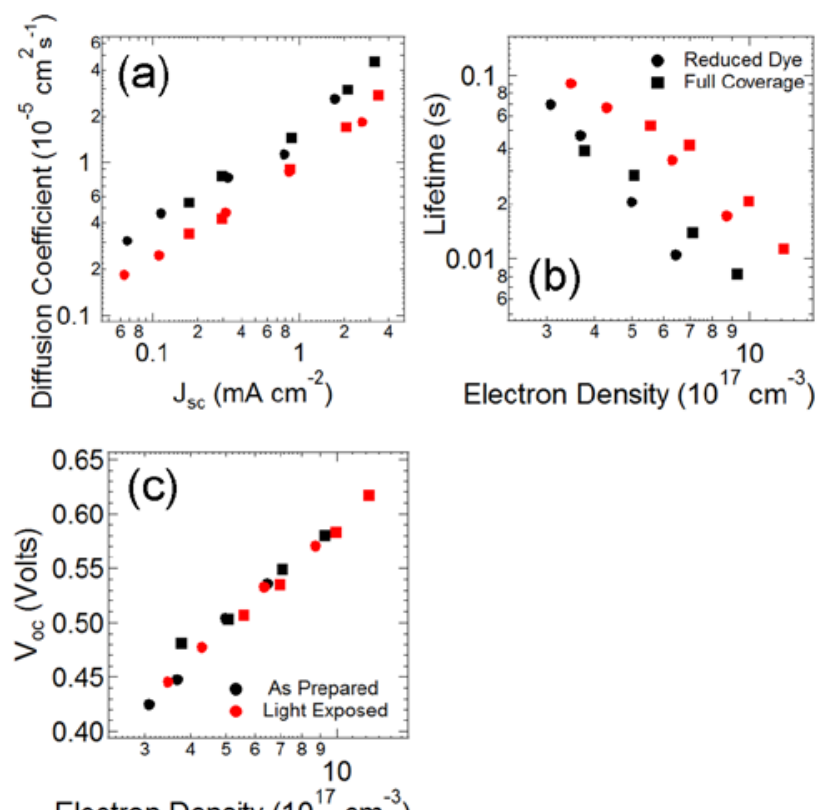

Figure 3. (a) Electron diffusion coefficient vs $J_{\mathrm{sc}}$, (b) electron lifetime vs electron density and (c) $V_{\text {oc }}$ vs electron density in the $\mathrm{TiO}_{2}$ film prior to (black) and following (red) light exposure for GD2-sensitized solar cells with full (squares) and reduced (circles) dye loadings. 
To measure electron density in the $\mathrm{TiO}_{2}$ film accurately, the electron diffusion length in DSSCs must be longer than the thickness of the $\mathrm{TiO}_{2}$ film employed. ${ }^{36}$ It is possible that charge collection losses due to a low diffusion length affect the $J_{\mathrm{sc}}$ in these devices. In this case, the increase in $J_{\mathrm{sc}}$ observed after light exposure could be due to an increased diffusion length. To check if the thickness of our devices is shorter than the electron diffusion length, the open circuit voltage at matched electron density was compared among DSSCs with a range of different $\mathrm{TiO}_{2}$ thicknesses (Figure 4(a)). As discussed earlier, the $V_{\text {oc }}$ vs $\log (\mathrm{ED})$ plot indicates the relative $\mathrm{TiO}_{2} E_{\mathrm{CB}}$ level, which should not be affected by the film thickness. The data measured here shows that the $V_{\text {oc }}$ vs $\log (E D)$ plots are invariant for both full and reduced dye loadings for film thicknesses between $1.6 \mu \mathrm{m}$ and $4.5 \mu \mathrm{m}$, and confirms the earlier observation that there are minimal shifts after light exposure. However, when the film thickness is increased to $6 \mu \mathrm{m}$ or higher, the plots begin to show a negative shift, that is, a shift towards higher $V_{\text {oc }}$ values at matched electron density. Since it is highly unlikely the $\mathrm{TiO}_{2}$ conduction band shifts negatively by up to $50 \mathrm{mV}$ simply by increasing the film thickness by $2 \mu \mathrm{m}$, this result suggests that there are some recombination losses during charge extraction for the $6 \mu \mathrm{m}$ films, and thus the electron density was underestimated. This leads to identical $V_{\text {oc }}$ values appearing to correlate with a lower charge density due to recombination, which manifests as the observed negative shift on the $V_{\text {oc }} \operatorname{vs} \log (\mathrm{ED})$ plot. This result implies that the diffusion length of these devices is approximately $5 \mu \mathrm{m}$ at open circuit. However, we note that previous studies of diffusion length have predicted and observed a decrease in diffusion length with decreased electron density. ${ }^{37,38}$ This arises due to a typically sub-linear recombination reaction order with respect to the redox mediator. To analyse whether such effects occur in the present porphyrin system, which would further reduce the diffusion length at the lower electron density values found at short circuit, we have computed the diffusion length $\left(L_{\mathrm{n}}\right)$ from transient measurements of the electron lifetime and diffusion coefficient. To ensure the same quasi Fermi level for measurements performed at open circuit (lifetime) and short circuit (diffusion coefficient), the 
electron density was determined at the appropriate circuit condition for each measurement. The diffusion length was then computed using values computed at identical electron densities using:

$$
L_{\mathrm{n}}=\left(\tau_{n} D_{n}\right)^{1 / 2}
$$

These results are shown in Figure 4(b). The diffusion length at open circuit was determined to be 5.6 $\mu \mathrm{m}$ for as prepared devices, and $5.9 \mu \mathrm{m}$ for light exposed devices from Equation (1). These values are consistent with the data from Figure 4(a) suggesting a diffusion length between 4.5 and $6.2 \mu \mathrm{m}$ at open circuit. Little change was observed as the electron density decreased, with values of $8.5 \mu \mathrm{m}$ (as prepared) and $8.3 \mu \mathrm{m}$ (light exposed) observed at the electron density equating to short circuit conditions under AM 1.5 illumination. The minimal change in diffusion length suggests either the linearity of recombination must be close to unity for these samples, or, alternatively, the subsequent analysis assumptions of linearization of recombination are invalid. The linearity of recombination was investigated by determining both the relationship between $V_{\text {ос }}$ and the logarithm of the light illumination, $\log \left(I_{0}\right)$, and the relationship between the logarithm of the lifetime, $\log \left(\tau_{n}\right)$ and the $V_{\text {oc }}$ This data is shown in Figure S6. Slopes of 70-72 mV were observed for the $V_{\text {oc }} \mathrm{Vs} \log \left(I_{0}\right)$ plots, and 12.5-13.3 $\mathrm{V}^{-1}$ for the $\log \left(\tau_{n}\right)$ vs $V_{\text {oc }}$ plots. Compared to the ideal values of $59 \mathrm{mV}$ and $16.9 \mathrm{~V}^{-1}$ respectively, these values yield consistent recombination reaction orders of $\gamma=0.79$ for as prepared devices and $\gamma=0.82$ for light exposed devices. Given the recently proposed linearity correction of Bisquert et al, where the diffusion length, $\lambda_{\mathrm{n}}$, is given by:

$$
\lambda_{\mathrm{n}}=\left(\frac{D_{0} n_{b}{ }^{1-\gamma} \tau_{0}}{\gamma}\right)^{1 / 2}
$$

where $D_{0}$ and $\tau_{0}$ are the free electron diffusion coefficient and lifetime respectively and $n_{\mathrm{b}}$ the background electron density, the diffusion length at short circuit predicted by Equation (2) exhibits a reduction by a factor of 1.4 (as prepared) or 1.3 (light exposed) compared to the value measured at open circuit. By applying these reduction factors to the open circuit diffusion length determined from Equation (1), the diffusion length at short circuit was estimated to be $4.0 \mu \mathrm{m}$ for as prepared, and $4.5 \mu \mathrm{m}$ 
for light exposed devices. The difference between short circuit values from Equation (1) and Equation (2) may arise from the photocurrent transient measurement technique not providing completely homogeneous electron density generation in the $\mathrm{TiO}_{2}$ film due to extraction at short circuit as previously reported. $^{38}$

The variation in device $J_{\mathrm{sc}}$ with film thickness also aids in estimating the diffusion length at short circuit. Figure 4(c) displays $J_{\text {sc }}$ data measured for films of different thickness and normalized to the largest observed value. At one sun intensity, the $J_{\mathrm{sc}}$ is observed to increase up to a thickness of $3.4 \mu \mathrm{m}$, and then remain constant within error between 3.4 and $6.0 \mu \mathrm{m}$. There is then a detectable decrease in $J_{\mathrm{sc}}$ when the $\mathrm{TiO}_{2}$ thickness is increased to $8.2 \mu \mathrm{m}$. This result suggests clear charge collection losses at a thickness of $8.2 \mu \mathrm{m}$, and a diffusion length in the range of $3.4 \mu \mathrm{m}-6.0 \mu \mathrm{m}$ at short circuit. Such an analysis is somewhat oversimplified since the light harvesting efficiency also increases with film thickness and could mask the onset of collection losses. We therefore calculated the $J_{\text {sc }}$ expected from each film thickness by first computing the IPCE using LHE $=1-10^{-\alpha d}$, where $\alpha$ is the molar absorption coefficient and $d$ the film thickness, then employing an injection efficiency of 0.65 estimated from a previous publication $^{25}$ and assuming no collection losses. Since light harvesting is almost quantitative in a $2 \mu \mathrm{m}$ film in the Soret absorption band due to the high molar extinction coefficient $\left(2 \times 10^{5} \mathrm{M}^{-1} \mathrm{~cm}^{-1}\right)$, only changes in the IPCE in the red region were computed using an average molar extinction coefficient of $8 \times 10^{3} \mathrm{M}^{-1} \mathrm{~cm}^{-1}$ between $500 \mathrm{~nm}$ and $650 \mathrm{~nm}$. The computed IPCE data was then integrated with the solar irradiance spectrum overlap to calculate an expected $J_{\text {sc }}$. These values appear as the yellow trend line in Figure 4(c). The measured $J_{\mathrm{sc}}$ increases are consistent with the increases expected from enhanced light harvesting up to $3.4 \mu \mathrm{m}$, suggesting no collection losses up to this film thickness. The measured $J_{\text {sc }}$ is clearly lower than the predicted value for a $6 \mu \mathrm{m}$ film, consistent with a short circuit diffusion length of $3.4-6 \mu \mathrm{m}$, in agreement with the predicted diffusion length at short circuit from Equation (2) and close to the value from Equation (1). Since the data in Figures 4(a)-4(c) collectively confirms that the 
short circuit diffusion length is longer than the $\mathrm{TiO}_{2}$ film thickness of $2.5 \mu \mathrm{m}$, it is concluded that changes in charge collection cannot be the origin of the observed device $J_{\mathrm{sc}}$ increase after light exposure. Based on these results, the $J_{\text {sc }}$ increase after light exposure is attributed to an improvement in charge generation. The exact origin of the improvement could be due either to an improved injection yield, faster injection kinetics, decreased fast recombination, or a combination of these alternatives.

Since our system for measuring voltage and current transients operates at reduced light intensity (maximum value $10 \mathrm{~mW} \mathrm{~cm}^{-2}$ ), we also attempted to confirm that the information determined from these measurements could be used to explain trends observed in $J-V$ measurements under $100 \mathrm{~mW} \mathrm{~cm}^{-2}$ illumination. For instance, the electron lifetime trends for the reduced dye loading samples in Figure 3(b) appear to be slightly diverging towards larger electron densities, and thus conclusions regarding the diffusion length and negligible charge collection losses determined at $10 \mathrm{~mW} \mathrm{~cm}{ }^{-2}$ may not be valid at $100 \mathrm{~mW} \mathrm{~cm}^{-2}$. To address this, the average relative increase in the photocurrent observed in four different DSSCs after light exposure was determined for both full and reduced dye loadings under AM 1.5 spectral irradiation at different illumination intensities (Figure 4(d)). This data verifies that the enhanced $J_{\text {sc }}$ improvement observed after light exposure for the reduced dye loading samples is consistent within experimental errors at reduced light intensities of $30 \mathrm{~mW} \mathrm{~cm}^{-2}$ and $12 \mathrm{~mW} \mathrm{~cm}^{-2}$. Figures 4(a) and 4(b) suggest with measurements on the transient system with an illumination power of up to $10 \mathrm{~mW} \mathrm{~cm}^{-2}$ that charge collection losses have little influence on performance in these DSSCs. Since the $J_{\mathrm{sc}}$ increases appear similar at $12 \mathrm{~mW} \mathrm{~cm}^{-2}, 30 \mathrm{~mW} \mathrm{~cm}^{-2}$ and $100 \mathrm{~mW} \mathrm{~cm}^{-2}$ light intensities, it is concluded that information obtained from the low light intensity source can be used to explain device trends measured under one sun illumination. This is supported by the measurements of $J_{\mathrm{sc}}$ at $100 \mathrm{~mW}$ $\mathrm{cm}^{-2}$ also implying minimal charge collection losses in these devices (Figure 4(c). 

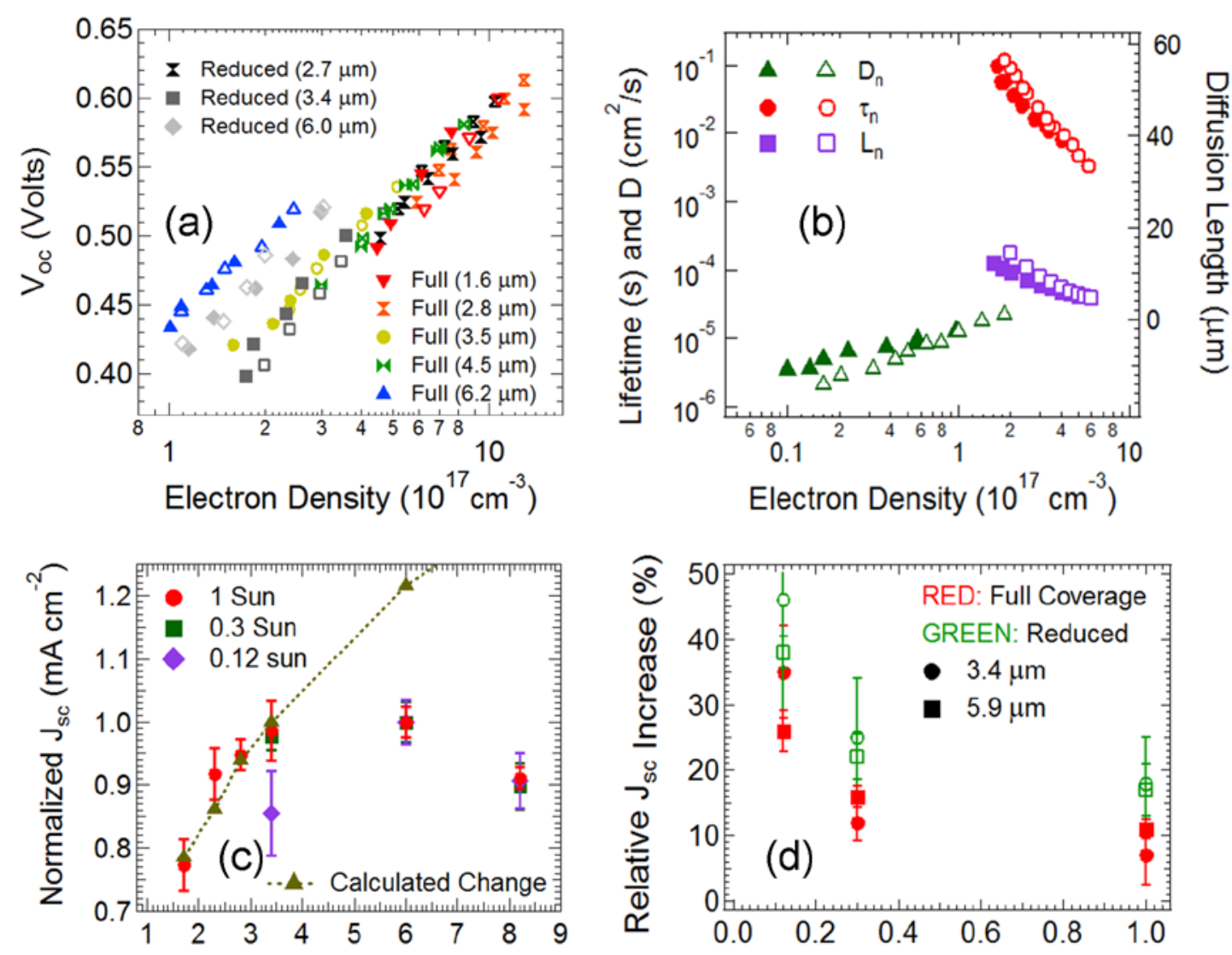

Film Thickness $(\mu \mathrm{m})$

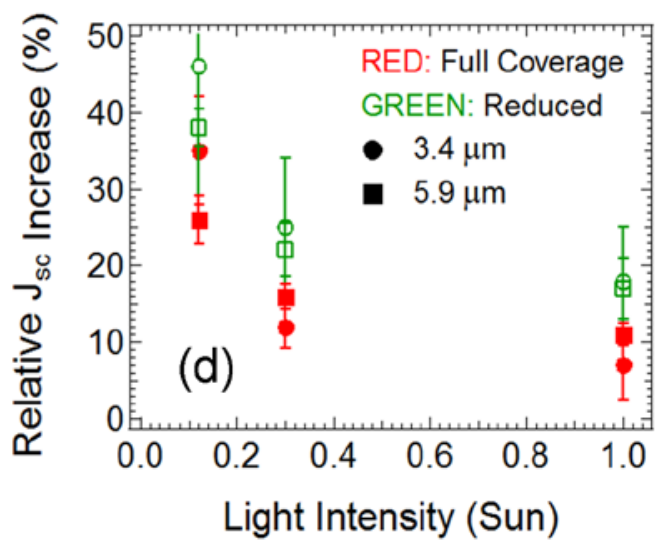

Figure 4: (a) $V_{o c}$ vs electron density in the $\mathrm{TiO}_{2}$ film prior to (solid symbols) and following (open symbols) light exposure for GD2-sensitized solar cells prepared with various film thicknesses. (b) Electron diffusion length calculated as $\left(D_{\mathrm{n}} \tau_{\mathrm{n}}\right)^{1 / 2}$ prior to (solid symbols) and following (open symbols) light exposure for devices with full dye loading. (c) Dependence of normalized $J_{\text {sc }}$ on film thickness for different illumination intensities. The $J_{\text {sc }}$ predicted from calculated IPCE changes is shown in yellow. and (d) Relative improvement in the $J_{\text {sc }}$ following light exposure for reduced (green) and full (red) dye loading at various illumination intensities. Measurements were performed for DSSCs prepared from 3.4 $\mu \mathrm{m}$ (circles) and $5.9 \mu \mathrm{m}$ (squares) $\mathrm{TiO}_{2}$ films.

\section{Variation of the Electrolyte Composition}

\section{Influence on $J-V$ Characteristics}

The nature of the cations employed in the electrolyte is known to have a significant impact on charge transfer processes in DSSCs, ${ }^{39-41}$ and may therefore effect the light exposure mechanism. To investigate the influence of electrolyte components on the light exposure mechanism, DSSCs were prepared with three different electrolyte compositions: a standard mixture (I), a dimethylpropylimidazolium $\left(\mathrm{DMPIm}^{+}\right)$-rich electrolyte, which contained no lithium or tert-butylpyridine (II), and a lithium-rich electrolyte which employed no DMPIm ${ }^{+}$or tert-butylpyridine (III). The ionic strength of the cations was 
maintained at $0.7 \mathrm{M}$ in all cases. The $J-V$ curves for DSSCs constructed from each electrolyte prior to and following a light exposure treatment are shown in Figure 5, with the photovoltaic performance parameters of these devices reported in Table 1.

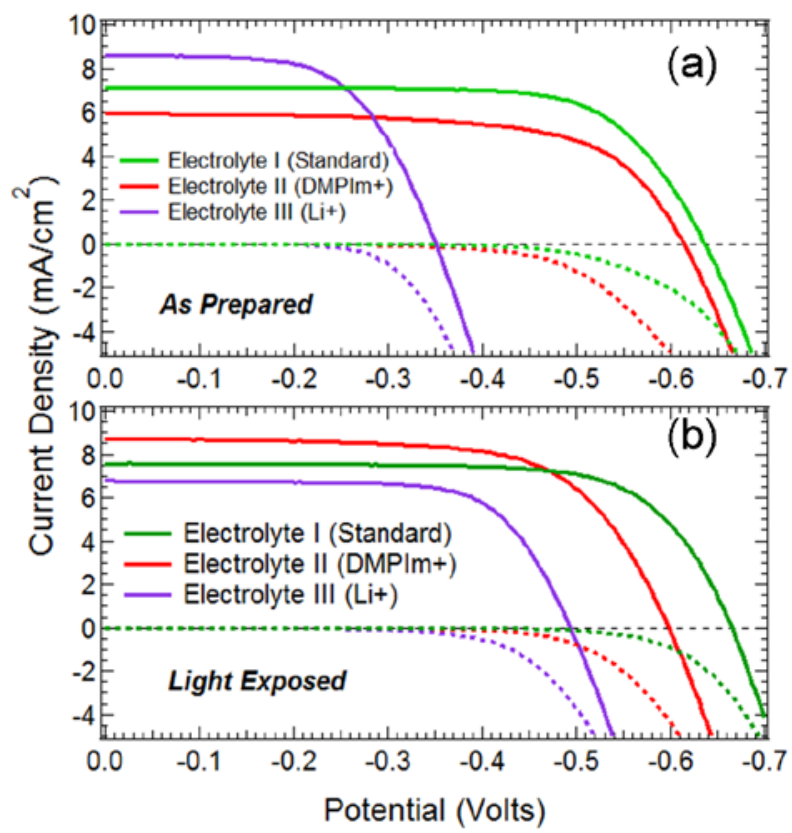

Figure 5. Current density-voltage curves for (a) as-prepared and (b) light exposed DSSCs prepared from porphyrin dye $\boldsymbol{G D} 2$ with three different electrolyte compositions.

Figure 5(a) shows that the $V_{\mathrm{oc}}$ and $J_{\mathrm{sc}}$ for as-prepared devices made with the DMPIm ${ }^{+}$electrolyte were both lower than those prepared with the standard electrolyte. As-prepared devices constructed from the $\mathrm{Li}^{+}$electrolyte exhibited a significantly reduced $V_{\text {oc }}$ but produced a higher $J_{\text {sc }}$ than those prepared with the standard electrolyte. After light exposure, Figure 5(b) demonstrates that the standard electrolyte device exhibited a $5 \%$ increase in the $V_{\text {oc }}$ with a simultaneous $5 \%$ increase in the $J_{\text {sc }}$. In contrast, light exposure reduced the $V_{\text {oc }}$ by $3 \%$ in the DMPIm ${ }^{+}$device, however the $J_{\text {sc }}$ was increased by $47 \%$. The devices containing the $\mathrm{Li}^{+}$electrolyte exhibited a $41 \%$ increase in the $V_{\text {oc }}$ after light exposure accompanied by a corresponding $21 \%$ reduction in the $J_{\mathrm{sc}}$.

Electron lifetimes and diffusion coefficients derived from transient photocurrent and photovoltage measurements are presented in Figure 6. The raw transients from which data is derived for Electrolyte 
II and III are shown in Figures S7-S10 (Supporting Information). The transients for the sample in standard electrolyte I were very similar to those shown earlier for a previous sample (Figure S2-S3) and are thus not reproduced.

Table 1. Photovoltaic parameters measured before and after light exposure for GD2 DSSCs prepared using electrolytes I, II, and III

\begin{tabular}{|c|c|c|c|c|c|c|c|c|}
\hline \multirow{2}{*}{ Electrolyte } & \multicolumn{2}{|c|}{$\boldsymbol{V}_{\boldsymbol{~ o c}} \mathbf{( m V )}$} & \multicolumn{2}{c|}{$\boldsymbol{J}_{\text {sc }} \mathbf{( m \mathbf { m } / \mathbf { c m } ^ { 2 } )}$} & \multicolumn{2}{c|}{ Fill Factor } & \multicolumn{2}{c|}{$\eta \mathbf{( \% )}$} \\
\cline { 2 - 9 } & $\begin{array}{c}\text { As } \\
\text { Prepared }\end{array}$ & $\begin{array}{c}\text { Light } \\
\text { Exposed }\end{array}$ & $\begin{array}{c}\text { As } \\
\text { Prepared }\end{array}$ & $\begin{array}{c}\text { Light } \\
\text { Exposed }\end{array}$ & $\begin{array}{c}\text { As } \\
\text { Prepared }\end{array}$ & $\begin{array}{c}\text { Light } \\
\text { Exposed }\end{array}$ & $\begin{array}{c}\text { As } \\
\text { Prepared }\end{array}$ & $\begin{array}{c}\text { Light } \\
\text { Exposed }\end{array}$ \\
\hline $\begin{array}{c}\text { I } \\
(\text { Standard) }\end{array}$ & 634 & 665 & 7.12 & 7.57 & 0.709 & 0.710 & 3.20 & 3.58 \\
\hline $\begin{array}{c}\text { II } \\
\left(\mathrm{DMPIm}^{+}\right)\end{array}$ & 612 & 598 & 5.94 & 8.72 & 0.653 & 0.659 & 2.37 & 3.44 \\
\hline $\begin{array}{c}\text { III } \\
\left(\mathrm{Li}^{+}\right)\end{array}$ & 350 & 494 & 8.61 & 6.78 & 0.601 & 0.697 & 1.81 & 2.34 \\
\hline
\end{tabular}

Figure 6(b) shows that the electron lifetime for the standard electrolyte is higher than that of both other electrolytes, with the DMPIm${ }^{+}$rich electrolyte exhibiting a slightly higher electron lifetime than the $\mathrm{Li}^{+}$ rich electrolyte at matched electron density. The $\mathrm{Li}^{+}$electrolyte also displays the lowest diffusion coefficient, with the DMPIm ${ }^{+}$electrolyte exhibiting the highest diffusion coefficient and the standard electrolyte producing a value between these two extremes. The $V_{\text {ос }}$ vs electron density plots in Figure 6(c), indicative of the $\mathrm{TiO}_{2} E_{\mathrm{CB}}$ value since the redox mediator concentration and solvent are identical for each electrolyte, demonstrate that devices prepared from the $\mathrm{Li}^{+}$electrolyte have the most positive $E_{\mathrm{CB}}$, whilst those prepared from the $\mathrm{DMPIm}^{+}$electrolyte have the most negative $E_{\mathrm{CB}}$. The standard electrolyte again exhibits an $E_{\mathrm{CB}}$ value between these two extremes. Light exposure of these devices produces an increase in the electron lifetime for each electrolyte. Figure 6(a) shows that the diffusion coefficients of the standard and DMPIm ${ }^{+}$electrolytes are reduced after light exposure, whilst that of the $\mathrm{Li}^{+}$electrolyte is increased. The $V_{\text {oc }}$ vs electron density plot indicates that the $E_{\mathrm{CB}}$ for the $\mathrm{Li}^{+}$electrolyte exhibits a significant negative shift upon light exposure, whilst the DMPIm ${ }^{+}$experiences a positive $E_{\mathrm{CB}}$ shift with respect to the NHE potential scale. There is no change to the $\mathrm{TiO}_{2}$ conduction band upon light 
exposure of the standard electrolyte as observed in both our previous measurements ${ }^{25}$ and those shown earlier in this work (Figure 3). We note that previous reports have suggested light exposure of DSSCs can lead to a change in the trap density of the $\mathrm{TiO}_{2}{ }^{26,27,42}$ The data in Figure 6 indicates that the slope of the $V_{\text {oc }}$ vs electron density plots remains constant for the standard electrolyte before and after light exposure, implying that the density of trap states in the semiconductor remains constant. For the $\mathrm{Li}^{+}$ electrolyte there appears to be little change in slope, whilst for the DMPIm ${ }^{+}$electrolyte, there is a small change in the slope. Changes in the slopes of these plots could represent changes in the trap density distribution in the $\mathrm{TiO}_{2}$. However, the slope divergence is most noticeable at lower energy levels, where the ratio of traps to total trap density is relatively low. Whilst the influence of a change in trap density on the photovoltaic performance cannot be excluded, the trends in $J-V$ data from Table 1 for the case of electrolyte II can be primarily accounted for by shifts in the $\mathrm{TiO}_{2}$ conduction bands as discussed below.
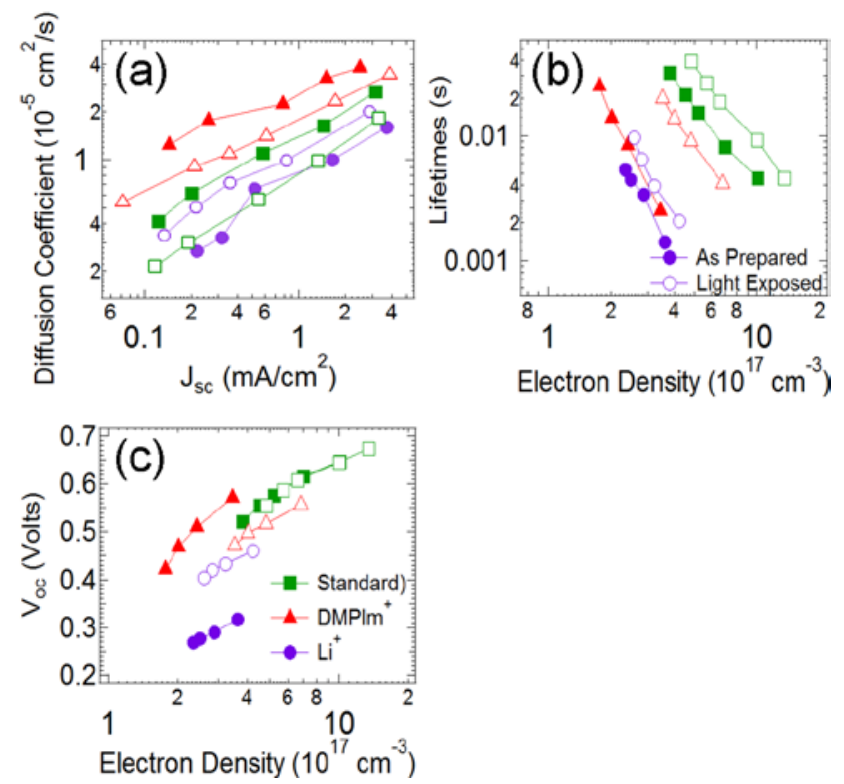

Figure 6. (a) Diffusion coefficient versus $J_{S C}$ (b) electron lifetime versus electron density, and (c) $V_{o c}$ versus electron density before (solid symbols) and after (open symbols) light exposure for GD2 DSSCs sensitized with electrolytes I (green squares), II (red triangles) and III (purple circles)

The light-induced $J_{\mathrm{sc}}$ and $V_{\mathrm{oc}}$ changes in each device can be largely rationalized based on the changes in the electron lifetime $(\tau)$ and $E_{\mathrm{CB}}$. The overall trends in electron lifetime, diffusion coefficients, $J_{\mathrm{sc}}$ and $V_{\text {oc }}$ in response to light exposure are summarized in Table 2, with possible causes of these trends 
discussed in further detail below. For as-prepared devices, the low $V_{\text {oc }}$ of the $\mathrm{Li}^{+}$electrolyte arises from a combination of a more positive $E_{\mathrm{CB}}$ position and the shortest electron lifetime. The DMPIm ${ }^{+}$device has a more negative $E_{\mathrm{CB}}$, however, the electron lifetime for this device is shorter than those prepared from the standard electrolyte, resulting in a lower electron density at open circuit, and consequently a lower $V_{\text {oc }}$ than the standard electrolyte. The $J_{\mathrm{sc}}$ trends are related to the comparative $E_{\mathrm{CB}}$ positions since shifts of this energy level directly alter the overlap between the $\mathrm{TiO}_{2}$ acceptor states and the dye LUMO orbital, often referred to as the driving force for injection $\left(\Delta \mathrm{G}_{\mathrm{inj}}\right)$. The $\mathrm{Li}^{+}$electrolyte, with the most positive $E_{\mathrm{CB}}$ and largest $\Delta \mathrm{G}_{\mathrm{inj}}$ is therefore expected to produce the highest $J_{\mathrm{sc}}$, whilst the DMPIm ${ }^{+}$ electrolyte, with the most negative $E_{\mathrm{CB}}$ and smallest $\Delta \mathrm{G}_{\text {inj }}$ produces the lowest $J_{\mathrm{sc}}$. Following light exposure, the $V_{\text {oc }}$ for the $\mathrm{Li}^{+}$device increases due to a negative $E_{\mathrm{CB}}$ shift and an increased electron lifetime. The DMPIm ${ }^{+} V_{\text {oc }}$ exhibits a reduced $V_{\text {oc }}$ due to significant positive $E_{\mathrm{CB}}$ shift, somewhat offset by a simultaneous increase in the electron lifetime. It is significant to note that although the $J_{\mathrm{sc}}$ trends for each electrolyte seem to be consistent with changes in $\Delta \mathrm{G}_{\mathrm{inj}}$ after light exposure, the $J_{\mathrm{sc}}$ for asprepared devices with the $\mathrm{Li}^{+}$electrolyte $\left(8.61 \mathrm{~mA} \mathrm{~cm}^{-2}\right)$ and light exposed devices using the DMPIm${ }^{+}$ electrolyte $\left(8.72 \mathrm{~mA} \mathrm{~cm}^{-2}\right)$ are almost identical despite a large difference in the $E_{\mathrm{CB}}$ for the two cases. Furthermore, comparing devices after light exposure, the $\mathrm{Li}^{+}$electrolyte still has a more positive $E_{\mathrm{CB}}$ than the DMPIm ${ }^{+}$, however the $J_{\text {sc }}$ for the $\mathrm{Li}^{+}$electrolyte $\left(6.78 \mathrm{~mA} \mathrm{~cm}{ }^{-2}\right)$ is significantly lower. This result cannot be explained by an injection yield that is dominated by the potential difference between the $\mathrm{TiO}_{2}$ conduction band and the dye LUMO only. One possible explanation for this is that the presence of lithium ions acts to impair the charge generation process, despite increasing the value of $\Delta \mathrm{G}_{\text {inj. }}$. 
Table 2. The origin of observed trends in various photovoltaic parameters following light exposure for GD2 DSSCs prepared using electrolytes I, II, and III

\begin{tabular}{|c|c|c|c|c|c|c|}
\hline \multirow[t]{2}{*}{ Parameter } & \multicolumn{2}{|c|}{ Electrolyte I (Standard) } & \multicolumn{2}{|c|}{ Electrolyte II (DMPIm $\left.{ }^{+}\right)$} & \multicolumn{2}{|c|}{ Electrolyte III ( $\left.\mathrm{Li}^{+}\right)$} \\
\hline & Trend & Dominant Cause & Trend & Dominant Cause & Trend & Dominant Cause \\
\hline $\mathrm{D}$ & Decrease & $\begin{array}{c}\mathrm{Li}^{+} \text {partially } \\
\text { complexed by tBP, } \\
\text { DMPIm } \\
\text { adsorption effect } \\
\text { dominates } \\
\end{array}$ & Decrease & $\begin{array}{l}\mathrm{DMPIm}^{+} \text {adsorbs } \\
\text { to } \mathrm{TiO}_{2} \text {, less } \\
\text { mobile ions and } \\
\mathrm{D}_{\text {ambipolar }} \text { lower }\end{array}$ & Increase & $\begin{array}{l}\text { Adsorbed } \mathrm{Li}^{+} \\
\text {removed, more } \\
\text { mobile ions and } \\
\mathrm{D}_{\text {ambipolar higher }}\end{array}$ \\
\hline$\tau$ & Increase & $\begin{array}{c}\text { Less } \mathrm{I}_{3}^{-} \text {in surface } \\
\text { region (Removal } \\
\text { of } \mathrm{Li}^{+} \text {and } \\
\text { blocking from } \\
\text { DMPIm }{ }^{+} \text {) }\end{array}$ & Increase & $\begin{array}{c}\mathrm{DMPIm}^{+} \text {surface } \\
\text { adsorption blocks } \\
\mathrm{I}_{3}^{-} \text {. Also } \Delta \mathrm{G}_{\text {recombine }} \\
\text { decreased }\end{array}$ & Increase & $\begin{array}{l}\text { Removal of } \mathrm{Li}^{+} \\
\text {from surface also } \\
\text { removes } \mathrm{I}_{3}^{-}\end{array}$ \\
\hline$J_{\mathrm{sc}}$ & Increase & $\begin{array}{c}\text { No change in } \\
\Delta \mathrm{G}_{\text {inj. }} \\
{ }^{*} i^{+} \text {initially } \\
\text { inhibits injection, } \\
\text { removal of } \mathrm{Li}^{+} \\
\text {increases } J_{S c}\end{array}$ & Increase & $\begin{array}{l}\Delta \mathrm{G}_{\text {inj }} \text { increased by } \\
\text { positive } E_{\mathrm{CB}} \text { shift }\end{array}$ & Decrease & $\begin{array}{c}\Delta \mathrm{G}_{\text {inj }} \text { decreased by } \\
\text { negative } E_{\mathrm{CB}} \text { shift. } \\
{ }^{*} \text { Li }^{+} \text {inhibits } \\
\text { injection. }\end{array}$ \\
\hline$V_{\text {oc }}$ & Increase & $\begin{array}{l}\text { Increased } \tau \text {, no } \\
\text { change in } E_{\mathrm{CB}}\end{array}$ & Decrease & $\begin{array}{l}\text { Positive } E_{\mathrm{CB}} \text { shift } \\
\text { (slightly mitigated } \\
\text { by increased } \tau \text { ) }\end{array}$ & Increase & $\begin{array}{c}\text { Increased } \tau \text { and } \\
\text { negative } E_{\mathrm{CB}} \text { shift }\end{array}$ \\
\hline
\end{tabular}

* Hypothesis proposed here.

\section{Mechanisms for the Changes in the Conduction Band Edge Potential, Charge Transport and}

\section{Recombination Kinetics.}

The major influence of the light exposure treatment across these three electrolytes appears to be a significant shift in the conduction band potential when only one cation is employed in the electrolyte. The relative conduction band positions are determined by the amount of surface charge on the $\mathrm{TiO}_{2}$, with $\mathrm{Li}^{+}$having the strongest impact on this parameter since it is known to adsorb to the $\mathrm{TiO}_{2}$ surface. ${ }^{42}$ The negative shift in $E_{\mathrm{CB}}$ induced by light exposure in devices containing the $\mathrm{Li}^{+}$electrolyte then suggests that $\mathrm{Li}^{+}$is being desorbed from the surface and diffusing into the bulk of the electrolyte, since there are no negative potential determining species that could adsorb to the $\mathrm{TiO}_{2}$. This premise is supported by the observed increase in the diffusion coefficient following light exposure. Since electron diffusion in DSSCs is typically described by an ambipolar transport mechansim, with cations from the electrolyte diffusing through the $\mathrm{TiO}_{2}$ pores in unison with electron movement in the nanoparticles, ${ }^{43}$ 
changes in the relative concentration of ions present in the surface and bulk regions of the electrolyte will affect electron diffusion. When adsorbed to the surface, electrons may be somewhat anchored around the vicinity of the immobilized ions, which are expected to have a different diffusion coefficient to the mobile cations. Assuming the ambipolar diffusion coefficient approaches the electron diffusion coefficient at high electron densities, the electron diffusion coefficient for this electrolyte is $1.5 \mathrm{x} 10^{-5}$ $\mathrm{cm}^{2} / \mathrm{s}$. With a lithium ion diffusion coefficient of $6 \times 10^{-7} \mathrm{~cm}^{2} / \mathrm{s}$ for the case of more mobile ions, dropping to $7 \times 10^{-8} \mathrm{~cm}^{2} / \mathrm{s}$ when more of the lithium ions are immobilized on the surface, removal of 40 $\%$ of $\mathrm{Li}^{+}$ions from the $\mathrm{TiO}_{2}$ surface upon light exposure would increase the ambipolar diffusion coefficient by the observed magnitude of $50 \%$ at the higher electron densities. Furthermore, the $\mathrm{Li}^{+}$ electrolyte shows a slightly improved electron lifetime after light exposure even though the negative $E_{\mathrm{CB}}$ shift creates a larger free energy driving force for recombination with the redox mediator $\left(\Delta G_{\text {recom }}\right)$ and the rate of recombination is expected to show a corresponding increase. ${ }^{44}$ This improvement in the lifetime can be explained by a movement of $\mathrm{Li}^{+}$ions away from the $\mathrm{TiO}_{2}$ surface accompanied by the simultaneous movement of $\mathrm{I}_{3}{ }^{-}$ions through Coulombic attraction, thereby increasing their distance from the $\mathrm{TiO}_{2}$ surface and decreasing the probability of reverse charge transfer.

For the case of the DMPIm ${ }^{+}$electrolyte, the positive $E_{\mathrm{CB}}$ shift induced in the DMPIm ${ }^{+}$electrolyte by light exposure implies that a positive potential determining species must be adsorbed to the $\mathrm{TiO}_{2}$. $\mathrm{The}$ positive $E_{\mathrm{CB}}$ shift is attributed to a light-induced surface adsorption of DMPIm ${ }^{+}$ions. The decreased diffusion coefficient following light exposure of this electrolyte is also consistent with this cation movement since immobilization of DMPIm ${ }^{+}$ions on the $\mathrm{TiO}_{2}$ surface would decrease the number of mobile cations participating in ambipolar diffusion. Using similar logic to that outlined for the lithium electrolyte, with an electron diffusion coefficient of $4.1 \times 10^{-5} \mathrm{~cm}^{2} / \mathrm{s}$ and ion diffusion coefficients of $1 \mathrm{x}$ $10^{-6} \mathrm{~cm}^{2} / \mathrm{s}$ for the case of more mobile ions, dropping to $1 \times 10^{-7} \mathrm{~cm}^{2} / \mathrm{s}$ when more of the imidazolium ions are immobilized on the surface, removal of $35 \%$ of $\mathrm{DMPIm}^{+}$ions from the $\mathrm{TiO}_{2}$ surface upon light exposure would increase the ambipolar diffusion coefficient by the observed magnitude of $30 \%$ at the 
higher electron densities. The increased electron lifetime is consistent with surface adsorption of $\mathrm{DMPIm}^{+}$since the positive $E_{\mathrm{CB}}$ shift induced by the adsorption decreases $\Delta \mathrm{G}$ for recombination, and the bulkier DMPIm ${ }^{+}$may also have a steric blocking effect on $\mathrm{I}_{3}{ }^{-}$at the surface

The unchanged $E_{\mathrm{CB}}$ for the standard electrolyte can be explained by competing $E_{\mathrm{CB}}$ shifts as one potential determining species $\left(\mathrm{Li}^{+}\right)$is removed from the $\mathrm{TiO}_{2}$ surface and replaced with another $\left(\mathrm{DMPIm}^{+}\right)$, leading to a minimal overall change. The dipole moments of these two cations are somewhat different, and it seems unlikely that an exchange of these cations would always occur with the same ratio. Thus we note that there may be minor changes to the $E_{\mathrm{CB}}$ upon light exposure of different devices, but repeated measurements of GD2-sensitized DSSCs within this work suggest this change is always small. The reduction in the standard electrolyte diffusion coefficient after light exposure is slightly more complex to explain, since $\mathrm{Li}^{+}$ions removed from the surface are replaced with adsorbed DMPIm ${ }^{+}$ions, thus the adsorbed ion concentration may be almost invariant. However, the presence of tert-butylpyridine (tBP) in the standard electrolyte may complex some of the mobile $\mathrm{Li}^{+}$ ions, such that some $\mathrm{Li}^{+}$participate differently in ambipolar diffusion. The net effect would then be that the DMPIm ${ }^{+}$cation adsorption dominates the diffusion coefficient behaviour. The presence of tBP in the standard electrolyte could also account for the higher electron lifetime of as-prepared devices since it could act as a blocking agent on the $\mathrm{TiO}_{2}$ surface to minimize recombination between $\mathrm{TiO}_{2}$ electrons and the acceptor species in the electrolyte. ${ }^{45}$ The removal of $\mathrm{Li}^{+}$and adsorption of DMPIm${ }^{+}$is also consistent with the increased lifetime in the standard electrolyte following light exposure, since both effects act to increase the electron lifetime.

The increase in $J_{\mathrm{sc}}$ for DSSCs prepared with a standard electrolyte arises from an improved internal quantum efficiency as we have previously reported. ${ }^{25}$ From the data in Figure 4 we have excluded an improvement in the charge collection yield since collection losses are minimal. It therefore appears that the improved photocurrent is due to either an improved injection yield, faster injection kinetics, the 
prevention of a fast recombination process, or a combination of all three alternatives. Without direct kinetic measurements of the injection dynamics on fast time scales it is difficult to distinguish between these possibilities. However, for the standard electrolyte it was earlier noted that the presence of lithium ions in the electrolyte shows a lower than expected photocurrent considering the relatively high value of $\Delta \mathrm{G}_{\mathrm{inj}}$ for this process. In the light-induced cation exchange process we propose here, these lithium ions would be removed from the surface region, potentially removing their limitation on the injection process or promotion of a fast recombination reaction and thus increasing the $J_{\mathrm{sc}}$.

\section{Variation of the Electrolyte Solvent Viscosity}

It was earlier noted that accumulation of electrons by application of a negative bias to the $\mathrm{TiO}_{2}$ electrode in the dark did not reproduce the same photovoltaic improvements as the light exposure effects, and furthermore, that exposing devices to a light treatment with infrared or UV-cutoff filters produced the same results as a light treatment with the full AM 1.5 spectrum. Coupled with the strong influence of dye loading on the magnitude of light-induced performance enhancements reported in Section I, these results suggest that photo-oxidation of the dye molecules plays a crucial role in the light exposure mechanism. To investigate the effect of dye oxidation on initiation of the DMPIm ${ }^{+}$cation insertion process, the electrolyte solvent viscosity was varied to slow down the dye regeneration by I' and alter the lifetime of oxidized dye molecules as has been previously reported. ${ }^{33,46}$

The photovoltaic performance parameters prior to and following light exposure of devices prepared with the $0.7 \mathrm{M}$ DMPImI and $0.05 \mathrm{M} \mathrm{I}$ electrolyte in various solvents (acetonitrile = ACN, methoxyacetonitrile $=\mathrm{MeO}-\mathrm{ACN}, \gamma$-butyrlactone $=\mathrm{GBL}$ and propylene carbonate $=\mathrm{PC}$ ) are recorded in Table 3. Corresponding IPCE and $J-V$ curves are displayed in Figure 7, whilst the viscosity, donor number and dielectric constants of each solvent are recorded in Table 4 . The $J_{\text {sc }}$ and $V_{\text {oc }}$ values of asprepared devices show a strong dependence on the electrolyte solvent. ACN-based devices show the lowest $J_{\text {sc }}$, whilst the higher viscosity solvents GBL and PC show a much greater photocurrent from as- 
prepared devices. However, this higher current is offset by a lower $V_{\text {oc }}$ for the GBL device, with the other three solvents showing approximately the same $V_{\text {oc }}$ After light exposure the ACN-based device shows the typical increase in $J_{\mathrm{sc}}$ and decrease in $V_{\text {oc }}$ for the DMPIm ${ }^{+}$electrolyte. The MeO-ACN-based device shows the same trends, although the relative decrease in $V_{\text {oc }}$ is much greater than for the ACN device. In contrast, the GBL and PC devices show large reductions in both the $J_{\text {sc }}$ and $V_{\text {oc }}$ following light exposure. Significant changes in the IPCE spectral shape after light exposure in these solvents, including loss of the characteristic porphyrin Q-bands and the emergence of a new absorption band around $700 \mathrm{~nm}$ (Figure S11) suggests this is mainly due to dye degradation under illumination.

Table 3: Photovoltaic performance parameters measured before and after light exposure for GD2 DSSCs containing DMPIm ${ }^{+}$rich electrolyte II in various solvents.

\begin{tabular}{|c|c|c|c|c|c|c|c|c|}
\hline \multirow{2}{*}{ Solvent } & \multicolumn{2}{|c|}{$V_{\text {oc }}(\mathbf{m V})$} & \multicolumn{2}{c|}{$J_{\text {sc }}\left(\mathbf{m A} / \mathbf{c m}^{2}\right)$} & \multicolumn{2}{c|}{ Fill Factor } & \multicolumn{2}{c|}{$\eta(\mathbf{\% )}$} \\
\cline { 2 - 10 } & $\begin{array}{c}\text { As } \\
\text { Prepared }\end{array}$ & $\begin{array}{c}\text { Light } \\
\text { Exposed }\end{array}$ & $\begin{array}{c}\text { As } \\
\text { Prepared }\end{array}$ & $\begin{array}{c}\text { Light } \\
\text { Exposed }\end{array}$ & $\begin{array}{c}\text { As } \\
\text { Prepared }\end{array}$ & $\begin{array}{c}\text { Light } \\
\text { Exposed }\end{array}$ & $\begin{array}{c}\text { As } \\
\text { Prepared }\end{array}$ & $\begin{array}{c}\text { Light } \\
\text { Exposed }\end{array}$ \\
\hline ACN & 607 & 580 & 5.24 & 9.11 & 0.597 & 0.646 & 1.90 & 3.41 \\
\hline MeO-ACN & 621 & 382 & 6.51 & 9.31 & 0.675 & 0.570 & 2.73 & 2.03 \\
\hline PC & 607 & 211 & 6.95 & 3.10 & 0.709 & 0.521 & 2.99 & 0.341 \\
\hline GBL & 589 & 159 & 8.52 & 1.13 & 0.665 & 0.504 & 3.29 & 0.091 \\
\hline
\end{tabular}

Figure 7 and Table 3 indicate that the photovoltaic performance parameters of the as-prepared GBL device are similar to those of the ACN device after light exposure. This result may imply that altering the solvent can achieve the same photovoltaic effect as light exposure for this dye. To further verify that the system properties are similar for as-prepared GBL and light exposed ACN devices, the electron lifetime and $\mathrm{TiO}_{2}$ conduction band potentials were compared. Figures 7(b) and 7(c) indicate that the higher $J_{\mathrm{sc}}$ and lower $V_{\mathrm{oc}}$ in as-prepared devices with more viscous solvents (GBL and PC) are accompanied by longer electron lifetimes and more positive relative shifts in the $\mathrm{TiO}_{2} E_{\mathrm{CB}}$. The lifetime and $\mathrm{TiO}_{2} E_{\mathrm{CB}}$ of the as-prepared GBL device are very similar to those of the light exposed ACN device, 
confirming the photovoltaic performance data suggesting changing the solvent can produce a similar system to light exposure of ACN devices.

Table 4: Physical properties of the organic solvents employed to alter the viscosity in the DMPIm ${ }^{+}$rich electrolyte II

\begin{tabular}{|c|c|c|c|}
\hline Solvent & Viscosity (cP) & Donor Number $^{\text {Dielectric Constant }}$ \\
\hline Acetonitrile (ACN) $^{[\mathrm{a}]}$ & 0.33 & 14.1 & 36.0 \\
\hline Methoxyacetonitrile (MeO-ACN) $^{[\mathrm{a}]}$ & 0.70 & 14.6 & 21.0 \\
\hline$\gamma$-butyrolactone (GBL) $^{[\mathrm{b}]}$ & 1.70 & 18.0 & 42.0 \\
\hline Propylene Carbonate (PC) $^{[\mathrm{b}]}$ & 2.50 & 15.1 & 65.0 \\
\hline
\end{tabular}

[a]. Solvent properties for ACN and MeOACN taken from reference [46] and [47]

[b]. Solvent properties for GBL and PC taken from reference [48].
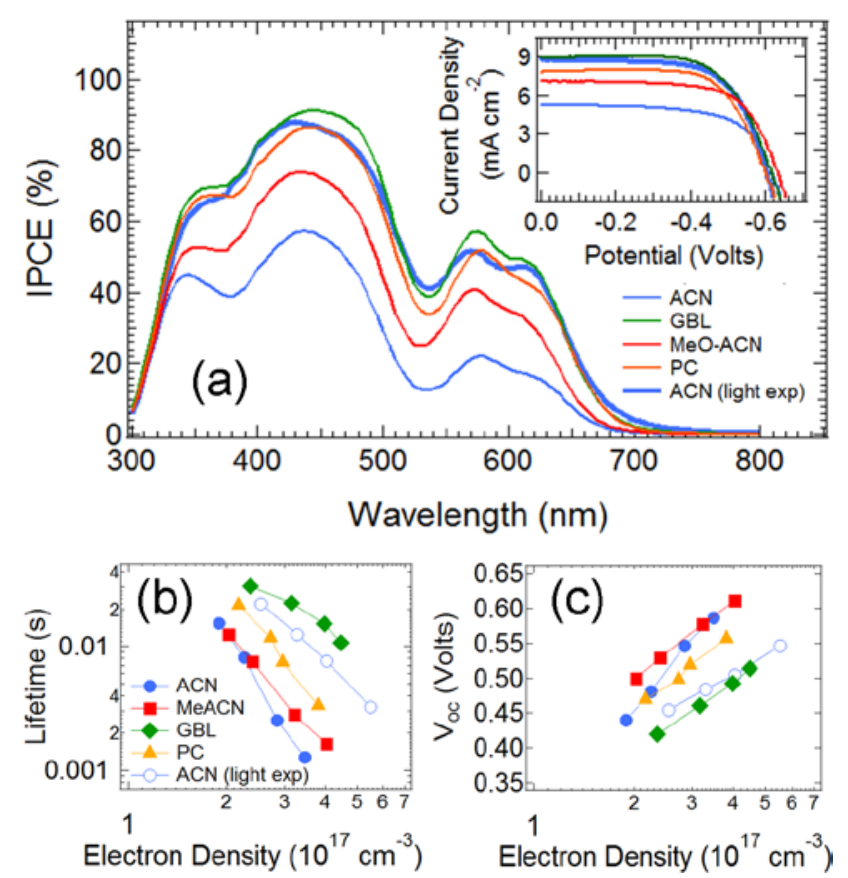

Figure 7. (a) IPCE and $J-V$ curves for as-prepared devices, (b) electron lifetime versus electron density and (c) $V_{o c}$ versus electron density for as prepared GD2 DSSCs containing DMPIm ${ }^{+}$rich electrolyte II with different solvents $(\mathrm{ACN}=$ blue circles, $\mathrm{MeO}-\mathrm{ACN}=$ red squares, $\mathrm{GBL}=$ green diamonds, $\mathrm{PC}=$ orange triangles). The respective data for a light exposed ACN device (open circles) is displayed as a reference.

It is clear that employing a solvent with higher viscosity and dielectric constant (GBL and PC) produces similar effects to those of light exposure in an ACN-based system, where the DMPIm ${ }^{+}$ions are thought 
to adsorb to the $\mathrm{TiO}_{2}$ surface. Previous reports have found that the $J_{\mathrm{sc}}$ and $V_{\text {oc }}$ of devices are dependent on the donor number of the electrolyte solvent, ${ }^{46,49}$ although in these studies, increases in $V_{\text {oc }}$ accompanied by decreases in $J_{\mathrm{sc}}$ were reported when the donor number of the solvent increased, whereas the trends observed in this study are not consistent with these reports, indeed showing the opposite correlation. However, it is still possible that the donor number of the solvent affects the equilibrium constant for adsorption of electrolyte cations to the $\mathrm{TiO}_{2}$ surface, producing different $\mathrm{TiO}_{2}$ surface energetics as previously reported. Alternatively, given the light exposure effect is initiated by photooxidation of the dye molecules, it is possible that the increased solvent viscosity leads to a longer dye cation lifetime due to slower regeneration from I', providing an accelerated light exposure effect. To distinguish between these two effects, the lifetime and conduction band potential of devices prepared in the GBL electrolyte were measured in the dark prior to any illumination using a recently published method. ${ }^{50}$ These values were then re-measured in the dark following acquisition of $J-V$ curve, and were finally measured under illumination from a diode laser. These results are shown in Figure 8.

Figure 8(a) shows that the electron lifetime and $\mathrm{TiO}_{2} E_{\mathrm{CB}}$ measured in the dark prior to any illumination are different from the values re-measured in the dark following $J-V$ testing and brief exposure to light. After $J-V$ testing ( 2 min, AM 1.5 illumination), the electron lifetime and $\mathrm{TiO}_{2} E_{\mathrm{CB}}$ are very similar when measured in the dark or under laser illumination. This difference in the dark lifetime measured before and after $J-V$ testing suggests that the $\mathrm{TiO}_{2}$ surface does not spontaneously form the higher performance state measured earlier in Figure 7 . Instead the $\sim 2$ minutes of light exposure during $J-V$ testing causes a change in the device properties, reflected by the lifetime measured in the dark and under illumination showing similar values after this $J-V$ testing. Furthermore, the induced changes involve an increase in the electron lifetime and a decrease in the $\mathrm{TiO}_{2} E_{\mathrm{CB}}$ (Figure 8(b)), identical trends to those induced by a longer light exposure treatment for devices containing ACN solvent. These results are consistent with the same mechanism producing the high performance state in both ACN and GBL devices, with only the kinetics of the cation exchange mechanism changing for the more viscous GBL 
solvent. We conclude that the solvent-dependent variation in as-prepared device performance is related to a change in the lifetime of the oxidized dye molecules in the more viscous solvent rather than different cation surface adsorption properties due to variations in the solvent donor number. This assignment is also supported by the observed dye degradation in these solvents under a prolonged light exposure treatment.
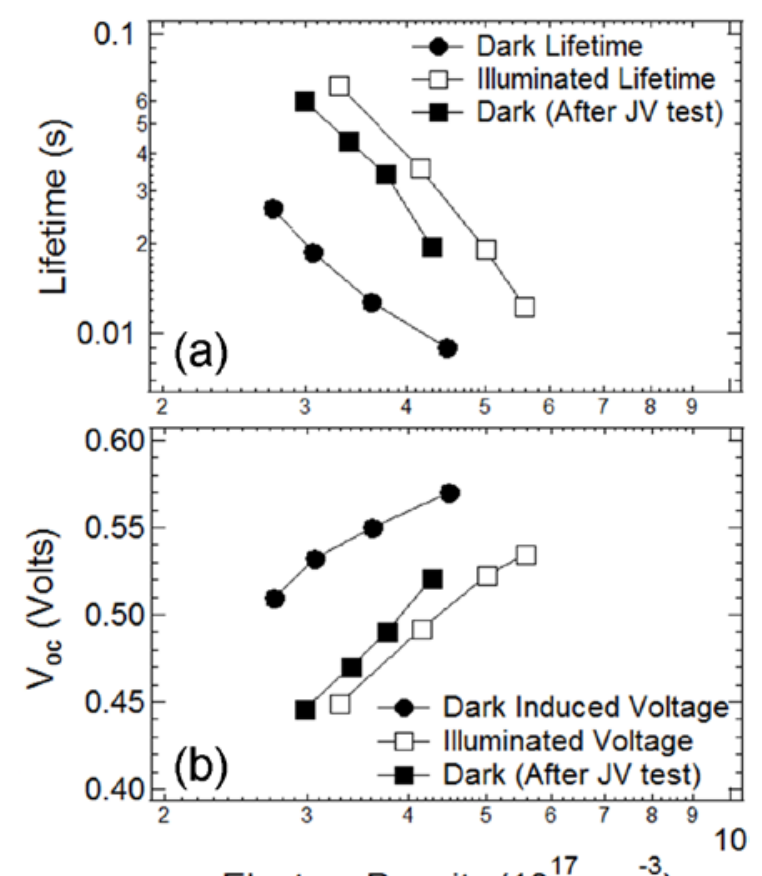

Figure 8. (a) Electron lifetime versus electron density and (b) $V_{O C}$ versus electron density measured in the dark prior to any light exposure (solid circles), then under illumination (open squares) and in the dark (solid squares) after $J-V$ measurements at AM 1.5 illumination for GD2 DSSCs containing $\mathrm{DMPIm}^{+}$rich electrolyte II with GBL as a solvent

\section{Dye Structure Dependence}

The cation exchange mechanism responsible for light-induced performance enhancements in GD2 DSSCs is consistent with all the above measurements; however, as we have only examined this single dye it is not clear whether this cation exchange mechanism is unique to this dye or whether it can be harnessed to boost the performance of other sensitizers. To gain more insight into the $\mathrm{Li}^{+}$removal process and why it originally limits injection or promotes fast recombination in GD2 DSSCs, a series of porphyrin dyes with different peripheral moieties and binding groups were prepared (see Figure 1) and 
incorporated into DSSCs. The photovoltaic performance parameters before and after light soaking are shown in Table 5 for a porphyrin dye (GD1) that has a similar porphyrin core to GD2 but which employs a cyanoacrylic acid binding group instead of a malonic acid group (Figure 9(a)). The electron lifetime, diffusion coefficient and $\mathrm{TiO}_{2} E_{\mathrm{CB}}$ values for this dye are compared to those of $\boldsymbol{G D 2}$-sensitized devices prior to and following light exposure in Figure 9.

Table 5. Photovoltaic parameters measured before and after light exposure for GD1 DSSCs prepared with electrolytes I, II and III

\begin{tabular}{|c|c|c|c|c|c|c|c|c|}
\hline \multirow{2}{*}{ Electrolyte } & \multicolumn{2}{|c|}{$V_{\boldsymbol{~ o c ~}}(\mathbf{m V})$} & \multicolumn{2}{c|}{$\boldsymbol{J}_{\text {sc }}\left(\mathbf{m A} / \mathbf{c m}^{2}\right)$} & \multicolumn{2}{c|}{ Fill Factor } & \multicolumn{2}{c|}{$\eta \mathbf{~ ( \% )}$} \\
\cline { 2 - 9 } & $\begin{array}{c}\text { As } \\
\text { Prepared }\end{array}$ & $\begin{array}{c}\text { Light } \\
\text { Exposed }\end{array}$ & $\begin{array}{c}\text { As } \\
\text { Prepared }\end{array}$ & $\begin{array}{c}\text { Light } \\
\text { Exposed }\end{array}$ & $\begin{array}{c}\text { As } \\
\text { Prepared }\end{array}$ & $\begin{array}{c}\text { Light } \\
\text { Exposed }\end{array}$ & $\begin{array}{c}\text { As } \\
\text { Prepared }\end{array}$ & $\begin{array}{c}\text { Light } \\
\text { Exposed }\end{array}$ \\
\hline $\begin{array}{c}\text { I } \\
\text { (Standard) }\end{array}$ & 567 & 594 & 4.80 & 4.22 & 0.669 & 0.697 & 1.82 & 1.75 \\
\hline $\begin{array}{c}\text { II } \\
(\mathrm{DMPIm}\end{array}$ & 503 & 530 & 2.61 & 6.36 & 0.576 & 0.637 & 0.756 & 2.15 \\
\hline $\begin{array}{c}\text { III } \\
\left(\mathrm{Li}^{+} \text {rich) }\right.\end{array}$ & 373 & 359 & 8.07 & 6.95 & 0.535 & 0.560 & 1.61 & 1.40 \\
\hline
\end{tabular}

The trends in electron lifetime (Figure 9(c)), diffusion coefficient (Figure 9(b)) and $\mathrm{TiO}_{2} E_{\mathrm{CB}}$ (Figure 9(d)) are identical for $\boldsymbol{G D 1}$ and $\boldsymbol{G D 2}$, both in the DMPIm${ }^{+}$electrolyte and the $\mathrm{Li}^{+}$electrolyte. This suggests that the cation exchange mechanism that produces these trends is common to both dyes under light exposure. In standard electrolyte, the $\boldsymbol{G D} \mathbf{1} V_{\text {ос }}$ is enhanced by the light exposure treatment whilst the $J_{\text {sc }}$ is decreased. The $V_{\text {oc }}$ enhancement is consistent with the cation exchange mechanism that replaces surface $\mathrm{Li}^{+}$with DMPIm ${ }^{+}$, a much bulkier cation which can more effectively block recombination between $\mathrm{TiO}_{2}$ electrons and the redox mediator. In GD2 devices, the light-induced photocurrent enhancement was associated with the removal of $\mathrm{Li}^{+}$, which is suspected to inhibit the initial charge generation process. However, for $\boldsymbol{G D} \mathbf{1}$ devices, the $\mathrm{Li}^{+}$electrolyte did not appear to have a negative effect on the charge generation. This can be confirmed by comparing the $J_{\text {sc }}$ for as-prepared GD1 devices with the $\mathrm{Li}^{+}$electrolyte $\left(8.07 \mathrm{~mA} \mathrm{~cm}^{-2}\right)$ and light exposed devices containing the DMPIm ${ }^{+}$ electrolyte (6.95 $\mathrm{mA} \mathrm{cm}^{-2}$ ), as was done earlier for $\boldsymbol{G D 2}$-sensitized devices. For GD1, the device containing the $\mathrm{Li}^{+}$electrolyte has a higher $J_{\mathrm{sc}}$, consistent with the much more positive $E_{\mathrm{CB}}$, which 
provides a much greater overlap between the dye LUMO and the $\mathrm{TiO}_{2}$ acceptor orbitals, in contrast to the results observed for $\boldsymbol{G D 2}$. This suggests that $\mathrm{Li}^{+}$ions in the surface region do not limit the injection for GD1 devices, and thus the light exposure effect can be explained by the conduction band potentialdependent injection yield. In order to probe whether this was the result of the slight change in porphyrin core substitution or a result of the binder configuration, other porphyrin dyes were investigated.

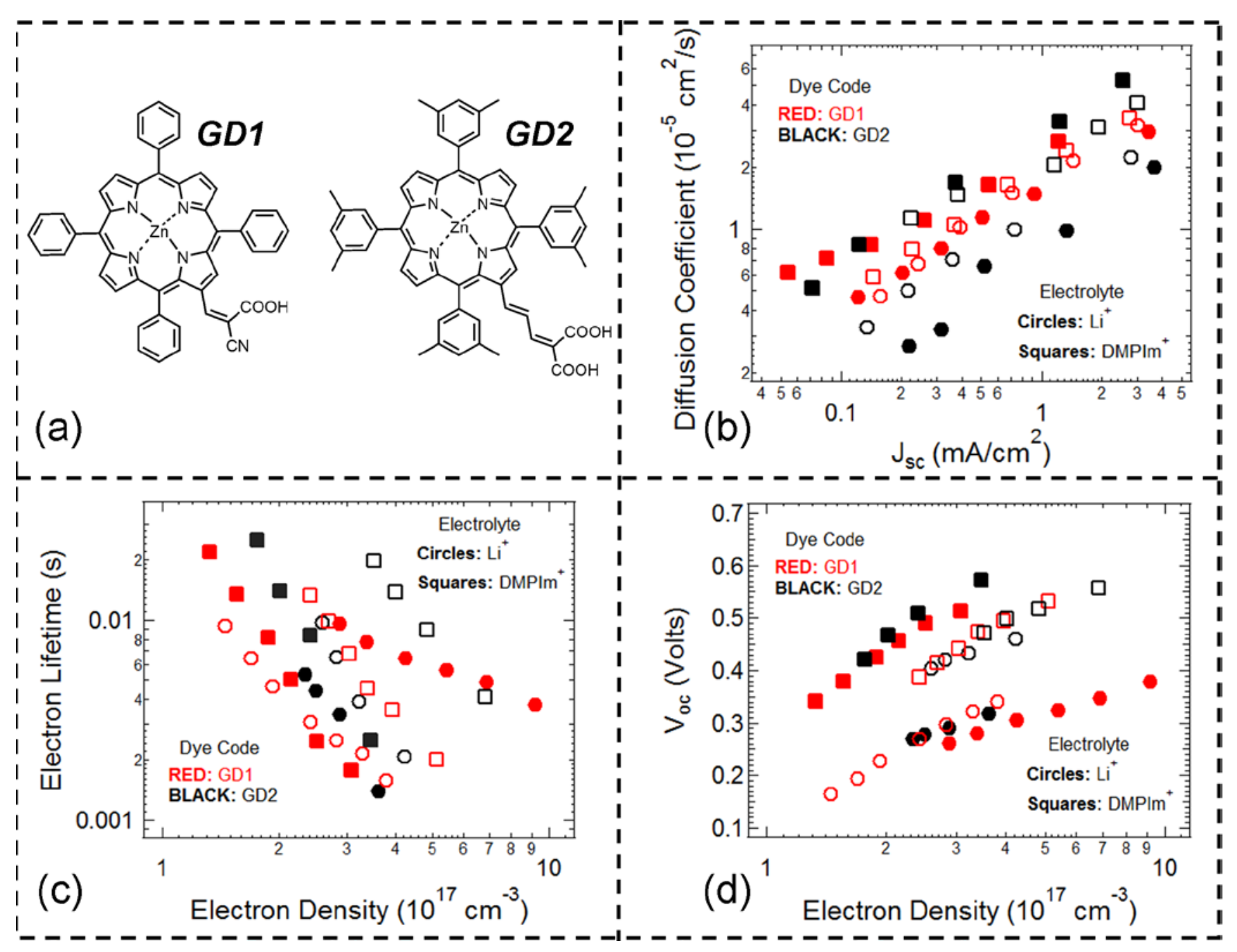

Figure 9. (a) Chemical structures, (b) diffusion coefficient vs $J_{s c}$, (c) electron lifetime vs electron density and (d) $V_{o c}$ vs electron density before (solid symbols) and after (open symbols) light exposure for $\boldsymbol{G D} 1$ and $\boldsymbol{G D 2}$ DSSCs containing DMPIm${ }^{+}$and $\mathrm{Li}^{+}$rich electrolytes.

Across several zinc porphyrin dyes tested, adding bulky tertiary-butyl (T1, Figure 1 and 10(a)) or even octyl substituents (P159, Figure 1 and 10(a)) at the meso position did not affect the trends in electron 
lifetime (Figure 10(c)), diffusion coefficient (Figure 10(b) and $\mathrm{TiO}_{2} E_{\mathrm{CB}}$ (Figure 10(d)) following light exposure. These trends were always accompanied by an increased $V_{\text {oc }}$ in standard electrolyte, consistent with the cation exchange mechanism which replaces surface $\mathrm{Li}^{+}$with $\mathrm{DMPIm}+$ (photovoltaic $^{+}$ performance data in Tables S1-S3). However, when focusing on the binding group used to anchor the dye to the $\mathrm{TiO}_{2}$ surface, a comparison between dyes with similar porphyrin cores but which employed either a simple carboxylic acid (P347, Figure 1 and 10(a)), cyanoacrylic acid (GD1, Figure 1 and 9(a)) or the multiple carboxylate malonic acid binding group (GD2, T1 and P159, Figure 1and 9(a)), only dyes which employed the malonic acid binder showed simultaneous $J_{\mathrm{sc}}$ increases after light exposure. Comparing the $J_{\mathrm{sc}}$ for as-prepared devices with the $\mathrm{Li}^{+}$electrolyte and light exposed devices containing the DMPIm ${ }^{+}$electrolyte showed that the currents scaled with changes in $\Delta \mathrm{G}_{\text {inj }}$ for devices with a single carboxylate group only, but those with the malonic acid binding group had lower than expected $J_{\text {sc }}$ values when the $\mathrm{Li}^{+}$electrolyte was employed. These results suggest that $\mathrm{Li}^{+}$ions either limit the injection or promote fast recombination in the dyes with a malonic acid binder, a limitation that subsequently disappears when the $\mathrm{Li}^{+}$is removed under light exposure. 


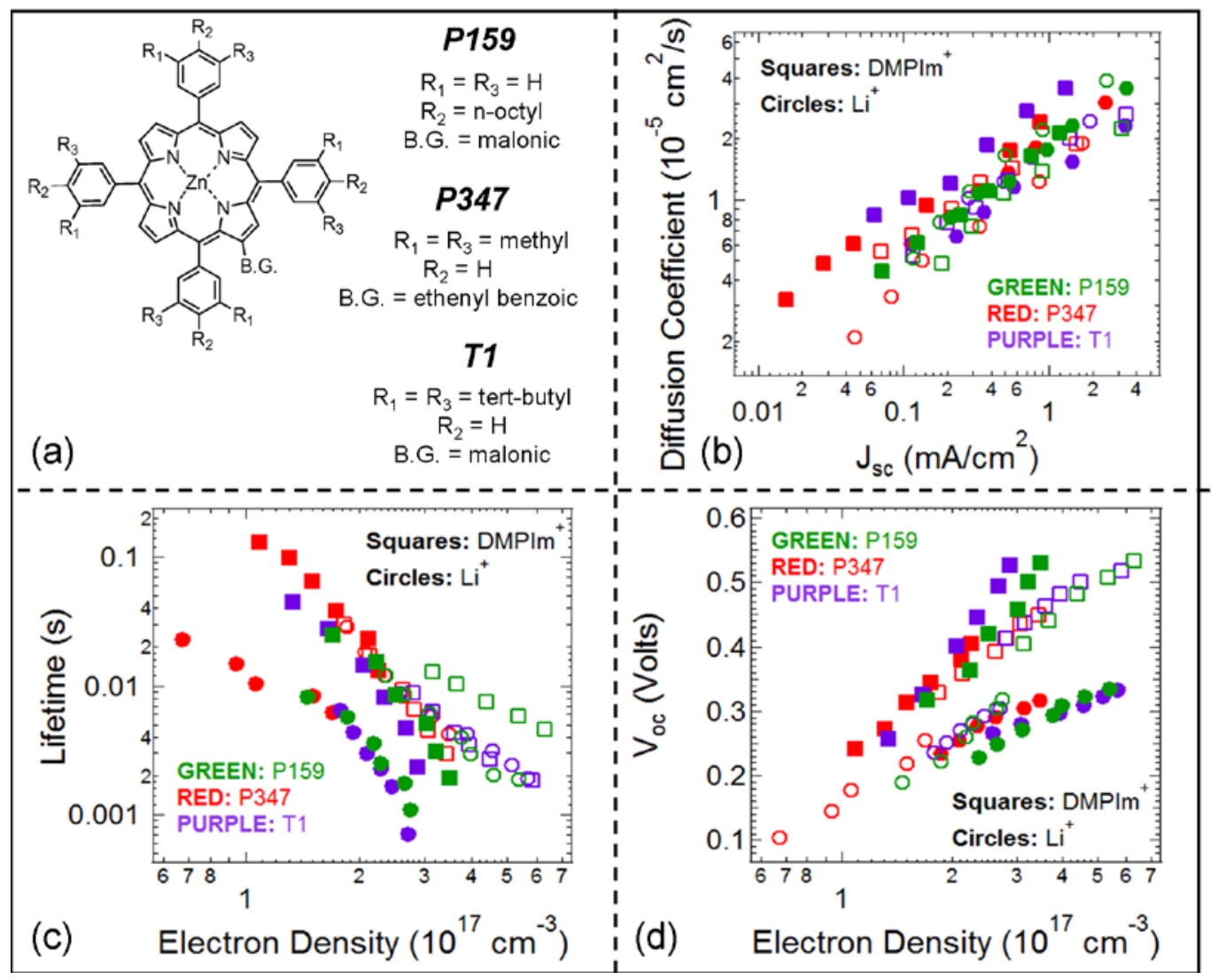

Figure 10. (a) Chemical structures, (b) diffusion coefficient vs $J_{s c}$, (c) electron lifetime vs electron density and (d) $V_{o c}$ vs electron density before (solid symbols) and after (open symbols) light exposure for DSSCs prepared with various zinc porphyrin dyes and containing DMPIm ${ }^{+}$and $\mathrm{Li}^{+}$rich electrolytes. Note that under the light intensity giving the order of $1 \mathrm{~ms}$ for the lifetime, diffusion length may not be long enough and thus, the electron density obtained by charge extraction may be underestimated.

Since the charge generation limitation is only apparent for dyes that possess binding moieties with two carboxylate groups, we propose that one of these groups initially associates with $\mathrm{Li}^{+}$ions rather than forming a bond to the $\mathrm{TiO}_{2}$. Upon illumination, the dye cation is created, which in turn initiates an exchange of cations at the $\mathrm{TiO}_{2}$ surface where $\mathrm{Li}^{+}$ions are replaced with DMPIm${ }^{+}$ions, as illustrated in Figure 11. Creation of the cation could repel $\mathrm{Li}^{+}$through either a Coulombic repulsion, or alternatively, by attracting $\mathrm{I}^{-}$ions towards the dye with $\mathrm{Li}^{+}$ions then following as a counterion. Removal of the surface $\mathrm{Li}^{+}$species allows the second $\mathrm{COO}^{-}$group to form a bond with the $\mathrm{TiO}_{2}$ and either enhance injection or decrease a fast recombination process, since the DMPIm ${ }^{+}$ions are too bulky to locate themselves between the dye binding group and the $\mathrm{TiO}_{2}$ surface and interfere with this process. 

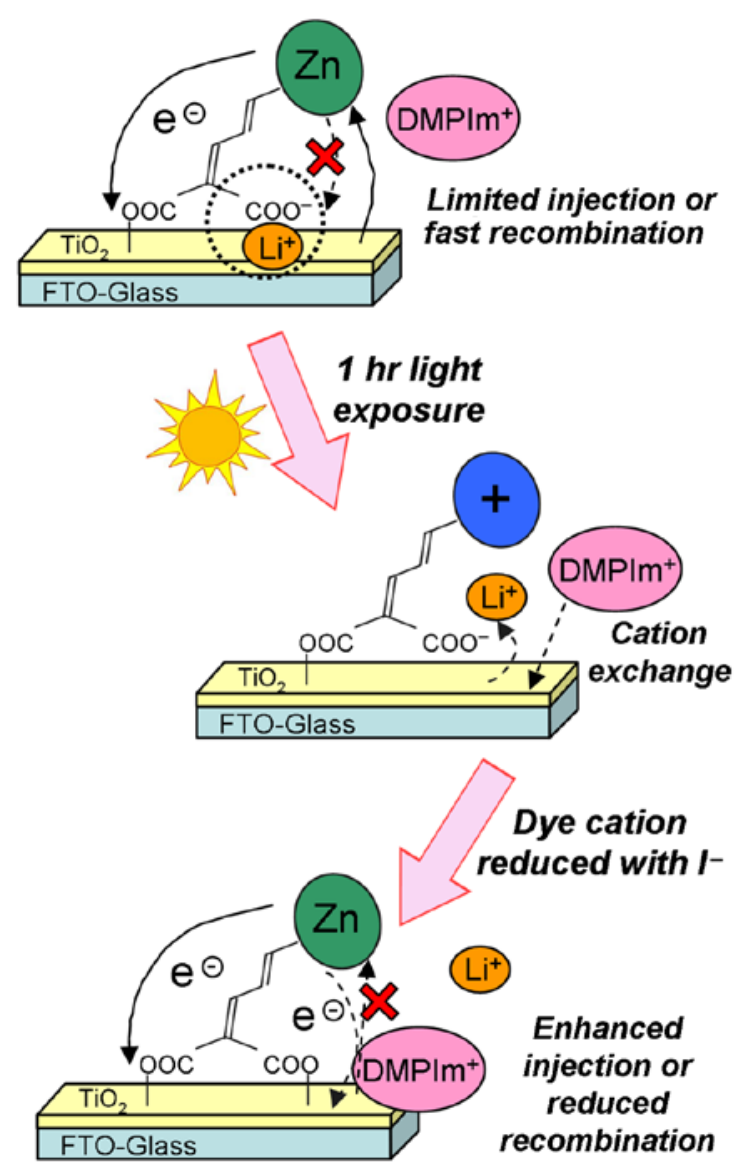

Figure 11. The proposed mechanism for simultaneous increases in the $J_{s c}, V_{o c}$ and fill factor of GD2sensitized $\mathrm{TiO}_{2}$ solar cells after a 1 hour light exposure treatment. Initial association of lithium with a carbonyl binding moiety limits injection or promotes fast recombination. Subsequent removal of lithium ions from the surface region under light exposure removes these limitations.

Based on these results, there appears to be general implications for other types of sensitizers exposed to light treatment. Provided there is enough open space at the surface to allow the cation exchange process observed in this study, a light treatment could be expected to lead to similar $V_{\text {oc }}$ increases. Furthermore, for dyes which employ multiple carboxylic acid binding groups in close proximity, such as the example in this study where two carboxylic acids are connected to a to a common carbon atom on the linker frame, $\mathrm{Li}^{+}$ions would be expected to affect either the injection into $\mathrm{TiO}_{2}$ or promote a fast recombination reaction. This limitation could be removed with a light exposure of these dyes, leading to improved device performance. 


\section{CONCLUSIONS}

The origin of improvements in the photovoltaic performance of zinc porphyrin dye-sensitized $\mathrm{TiO}_{2}$ solar cells under white light illumination has been elucidated. Detailed examinations of photovoltage and photocurrent transients for devices prepared using various electrolyte compositions have indicated that enhancements in the $J_{\mathrm{sc}}$ and $V_{\mathrm{oc}}$ are consistent with a light-induced exchange of cations in the electrolyte. Under illumination, $\mathrm{Li}^{+}$ions are removed from the $\mathrm{TiO}_{2}$ surface and replaced with $\mathrm{DMPIm}^{+}$ ions, a process which enhances the electron lifetime by decreasing recombination with the redox mediator. Similar effects were not replicated by application of negative bias under dark conditions. Variation of the electrolyte solvent viscosity indicated that the performance of devices could be increased to levels close to those achieved after light exposure in acetonitrile, with subsequent comparisons of the electron lifetime in the dark and under illumination revealing that these changes reflected an accelerated rate of light-induced performance enhancements in more viscous solvents. These results were consistent with a light exposure effect initiated by formation of dye cation molecules following photo-excitation rather than photoinduced changes in the semiconductor surface states. The peripheral moiety and type of linker group on the porphyrin chromophore were both varied in order to investigate the structural features of the dyes which make them susceptible to light-induced improvements in the $J_{\mathrm{sc}}$. Enhanced $J_{\mathrm{sc}}$ as a result of light exposure was only measured for dyes possessing two carboxylic acid binding groups, a feature arising from the light-induced removal of the $\mathrm{Li}^{+}$that initially either limits injection or promotes fast recombination at the dye/TiO 2 interface. We conclude that light exposure may produce increases in the $V_{\text {oc }}$ of dyes with open space at the $\mathrm{TiO}_{2}$ surface, such as planar or poorly stacked molecules, due to the electrolyte cation exchange. For dyes that employ multiple carboxylate binding groups and show charge generation limitations such as the porphyrins studied here, simultaneous improvements in $J_{\mathrm{sc}}$ may also be possible. 


\section{ACKNOWLEDGEMENT}

The support of the Australian Research Council through the ARC Center of Excellence, Federation Fellowship, Discovery, and LIEF schemes is gratefully acknowledged. MJG acknowledges the support of a Prime Minister's Australia Asia Endeavour Award from the Australian Department of Education, Employment and Workplace Relations.

\section{SUPPORTING INFORMATION AVAILABLE}

The change in $V_{o c}, J_{s c}$ and fill factor observed for GD2-sensitzed solar cells containing DMPIm ${ }^{+}$rich electrolyte II after application of an external bias in the dark for 1 hour (Figure S1). The dependence of $V_{\text {oc }}$ on the light intensity, and the electron lifetime on device $V_{\text {oc }}$ for selected $G \boldsymbol{D} 2$ devices prior to and following light exposure (Figure S6). Photocurrent, photovoltage and extracted charge transients prior to and following light exposure for devices prepared with electrolytes I (Figures S2-S5), II (Figure S7-S8) and III (Figure S9-S10). IPCE curves following light exposure of devices prepared using electrolyte II in various solvents (Figure S11). This information is available free of charge via the Internet at $\underline{\text { http://pubs.acs.org }}$

\section{REFERENCES}

(1) O'Regan, B.; Grätzel, M., A Low-Cost, High-Efficiency Solar Cell Based on DyeSensitized Colloidal $\mathrm{TiO}_{2}$ Films, Nature, 1991, 353, 737-740.

(2) Hagfeldt, A.; Gratzel, M., Light-Induced Redox Reactions in Nanocrystalline Systems, Chem. Rev., 1995, 95, 49-68.

(3) Grätzel, M., Dye Sensitized Solar Cells, J. Photochem. Photobiol. C, 2003, 4, 145-153. 
Durrant, J. R., Charge Separation Versus Recombination in Dye Sensitized Solar Cells: The Minimization of Kinetic Redundancy, J. Am. Chem. Soc., 2005, 127, 3456-3462.

(5) Chiba, Y.; Islam, A.; Watanabe, Y.; Komiya, R.; Koide, N.; Han, L., Dye Sensitized Solar Cells With Conversion Efficiency of 11.1\%, Jap. J. App. Phys., 2006, 45, L638-L640.

(6) Yu, Q.; Wang, Y.; Yi, Z.; Zu, N.; Zhang, J.; Zhang, M.; Wang, P., High-Efficiency DyeSensitized Solar Cells: The Influence of Lithium Ions on Exciton Dissociation, Charge Recombination and Surface States, ACS Nano, 2010, 4, 6032-6038.

(7) Yella, A.; Lee, H.-W.; Tsao, H. N.; Yi, C.; Chandiran, A. K.; Nazeeruddin, M. K.; Diau, E. W.-G.; Yeh, C.-Y.; Zakeeruddin, S. M.; Grätzel, M., Porphyrin-Sensitized Solar Cells with Cobalt (II/III)-Based Redox Electrolyte Exceed 12 Percent Efficiency, Science, 2011, 334, 629-634.

(8) Bessho, T.; Zakeeruddin, S. M.; Yeh, C.-Y.; Diau, E. W.-G.; Grätzel, M., Highly Efficient Mesoscopic Dye-Sensitized Solar Cells Based on Donor-Acceptor-Substituted Porphyrins, Angew. Chem. Int. Ed., 2010, 49, 6646-6649.

(9) Campbell, W. M.; Burrell, A. K.; Officer, D. L.; Jolley, K. W., Porphyrins as Light Harvesters in the Dye Sensitized Solar Cell, Coord. Chem. Rev., 2004, 248, 1363-1379.

(10) Dos Santos, T.; Morandeira, A.; Koops, S.; Mozer, A. J.; Tsekouras, G.; Dong, Y.; Wagner, P.; Wallace, G.; Earles, J. C.; Gordon, K. C.; Officer, D. L.; Durrant, J. R., Injection Limitations in a Series of Porphyrin Dye Sensitized Solar Cells, J. Phys. Chem. C, 2010, 114, 32763279.

(11) Koehorst, R. B. M.; Boschloo, G. K.; Savenije, T. J.; Goossens, A.; Schaafsma, T. J., Spectral Sensitization of $\mathrm{TiO}_{2}$ Substrates by Monolayers of Porphyrin Heterodimers, J. Phys. Chem. B, 2000, 104, 2371-2377.

(12) Mozer, A. J.; Griffith, M. J.; Tsekouras, G.; Wagner, P.; Wallace, G. G.; Mori, S.; Sunahara, K.; Miyashita, M.; Earles, J. C.; Gordon, K. C.; Du, L.; Katoh, R.; Furube, A.; Officer, D. L., Zn-Zn Porphyrin Dimer-Sensitised Solar Cells: Towards 3-D Light Harvesting, J. Am. Chem. Soc., 2009, 131, 15621-15623. 
(13) Lin, C.-Y.; Lo, C.-F.; Luo, L.; Lu, H.-P.; Hung, C.-S.; Diau, E. W.-G., Design and Characterization of Novel Porphyrins with Oligo(phenylethylnyl) Links of Varied Length for DyeSensitized Solar Cells: Synthesis and Optical, Electrochemical, and Photovoltaic Investigation, J. Phys. Chem. C, 2009, 113, 755-764.

(14) Imahori, H., Porphyrins as Potential Sensitizers for Dye Sensitized Solar Cells, Key Eng. Mater., 2010, 451, 29-40.

(15) Clifford, J. N.; Forneli, A.; Chen, H.; Torres, T.; Tan, S.; Palomares, E., Co-Sensitized DSCs: Dye Selection Criteria for Optimized Device $V_{\text {ос }}$ and Efficiency, J. Mater. Chem., 2011, 21, 1693-1696.

(16) Imahori, H.; Umeyama, T.; Ito, S., Large $\pi$-aromatic Molecules as Potential Sensitizers for Highly Efficient Dye Sensitized Solar Cells, Acc. Chem. Res., 2009, 42, 1809-1818.

(17) Liu, Y.; Lin, H.; Dy, J. T.; Tamaki, K.; Nakazaki, J.; Nakayama, D.; Uchida, S.; Kubo, T.; Segawa, H., N-fused Carbazole-Zinc Porphyrin-Free-Base Porphyrin Triad for Efficient Near-IR Dye-Sensitized Solar Cells, Chem. Comm., 2011, 47, 4010-4012.

(18) Mozer, A. J.; Wagner, P.; Officer, D. L.; Wallace, G. G.; Campbell, W. M.; Miyashita, M.; Sunaharac, K.; Mori, S., The Origin of Open Circuit Voltage of Porphyrin-Sensitised $\mathrm{TiO}_{2} \mathrm{Solar}$ Cells, Chem. Comm., 2008, 4741-4743.

(19) Imahori, H.; Kang, S.; Hayashi, H.; Haruta, M.; Kurata, H.; Isoda, S.; Canton, S. E.; Infahsaeng, Y.; Kathiravan, A.; Pascher, T.; Chabera, P.; Yartsev, A. P.; Sundstrom, V., Photoinduced Charge Carrier Dynamics of Zn-Porphyrin- $\mathrm{TiO}_{2}$ Electrodes: The Key Role of Charge Recombination for Solar Cell Performance, J. Phys. Chem. A, 2011, 115, 3679-3690.

(20) Griffith, M. J.; Sunahara, K.; Wagner, P.; Wagner, K.; Wallace, G. G.; Officer, D. L.; Furube, A.; Katoh, R.; Mori, S.; Mozer, A. J., Porphyrins for Dye-Sensitised Solar Cells: New Insights into Efficiency-Determining Electron Transfer Steps, Chem. Comm., 2012, 48, 4145-4162.

(21) Forneli, A.; Planells, M.; Angele, M.; Sarmentero; Martinez-Ferrero, E.; O’Regan, B. C.; Ballester, P.; Palomares, E., The Role of Para-Alkyl Substituents on Meso-Phenyl Porphyrin Sensitised 
$\mathrm{TiO}_{2}$ Solar Cells: Control of the $\mathrm{e}_{\mathrm{TiO} 2} /$ Electrolyte ${ }^{+}$Recombination Reaction, J. Mater. Chem., 2008, 18, 1652-1658.

(22) Imahori, H.; Matsubara, Y.; Iijima, H.; Umeyama, T.; Matano, Y.; Ito, S.; Niemi, M.; Tkachenko, N. V.; Lemmetyinen, H., Effects of Meso-Diarylamino Group of Porphyrins as Sensitizers in Dye Sensitized Solar Cells on Optical, Electrochemical, and Photovoltaic Properties, J. Phys. Chem. C, 2010, 114, 10656-10665.

(23) Hsieh, C.-P.; Lu, H.-P.; Chiu, C.-L.; Lee, C.-W.; Chuang, S.-H.; Mai, C.-L.; Yen, W.-N.; Hsu, S.-J.; Diau, E. W.-G.; Yeh, C.-Y., Synthesis and Characterization of Porphyrin Sensitizers With Various Electron-Donating Substituents for Highly Efficient Dye-Sensitized Solar Cells, J. Mater. Chem., 2010, 20, 1127-1134.

(24) Stromberg, J. R.; Marton, A.; Kee, H. L.; Kirmaier, C.; Diers, J. R.; Muthiah, C.; Taniguchi, M.; Lindsey, J. S.; Bocian, D. F.; Meyer, G. J.; Holten, D., Examination of Tethered Porphyrin, Chlorin, and Bacteriochlorin Molecules in Mesoporous Metal-Oxide Solar Cells, J. Phys. Chem. C, 2007, 111, 15464-15478.

(25) Wagner, K.; Griffith, M. J.; James, M.; Mozer, A. J.; Wagner, P.; Triani, G.; Officer, D. L.; Wallace, G. G., Significant Performance Improvement of Porphyrin-Sensitised $\mathrm{TiO}_{2}$ Solar Cells Under White Light Illumination, J. Phys. Chem. C, 2011, 115, 317-326.

(26) Wang, Q.; Zhang, Z.; Zakeeruddin, S. M.; Grätzel, M., Enhancement of the Performance of Dye Sensitized Solar Cells by Formation of Shallow Transport Levels Under Visible Light Illumination, J. Phys. Chem. C, 2008, 112, 7084-7092.

(27) Gregg, B. A.; Chen, S.-G.; Ferrere, S., Enhanced Dye-Sensitized Photoconversion Efficiency via Reversible Production of UV-Induced Surface States in Nanoporous $\mathrm{TiO}_{2}$, J. Phys. Chem. C, 2003, 107, 3019-3029.

(28) Sauvage, F.; Fischer, M. K. R.; Mishra, A.; Zakeeruddin, S. M.; Nazeeruddin, M. K.; Bäuerle, P.; Grätzel, M., A Dendritic Oligothiophene Ruthenium Sensitizer for Stable Dye Sensitized Solar Cells, Chem. Sus. En. Mater., 2009, 2, 761-768. 
(29) Listorti, A; Creager, C; Sommeling, P; Kroon, J; Palomares, E; Fornelli, A; Breen, B;

Barnes, P. R. F; Durrant, J. R; Law, C; O’Regan, B., The Mechanism Behind the Beneficial Effect of Light Soaking on Injection Efficiency and Photocurrent in Dye Sensitized Solar Cells, Ener. Environ. Sci., 2011, 4, 3494-3501.

(30) Campbell, W. M.; Jolley, K. W.; Wagner, P.; Wagner, K.; Walsh, P. J.; Gordon, K. C.; Schmidt-Mende, L.; Nazeeruddin, M. K.; Wang, Q.; Grätzel, M.; Officer, D. L., Zn Porphyrins as Highly Efficient Sensitizers in Dye Sensitized Solar Cells, J. Phys. Chem. C, 2007, 111, 11760-11762.

(31) Wang, Q.; Campbell, W. M.; Bonfantani, E. E.; Jolley, K. W.; Officer, D. L.; Walsh, P. J.; Gordon, K.; Humphry-Baker, R.; Nazeeruddin, M. K.; Grätzel, M., Efficient Light Harvesting by Using Green Zn-Porphyrin-Sensitized Nanocrystalline $\mathrm{TiO}_{2}$ Films, J. Phys. Chem. B, 2005, 109, 1539715409.

(32) Ito, S.; Nazeeruddin, M. K.; Liska, P.; Comte, P.; Charvet, R.; Pechy, P.; Jirousek, M.; Kay, A.; Zakeeruddin, S. M.; Grätzel, M., Photovoltaic Characterization of Dye Sensitized Solar Cells: Effect of Device Masking on Conversion Efficiency, Prog. Photovol. Res. App., 2006, 14, 589-601.

(33) Nakade, S.; Kanzaki, T.; Wada, Y.; Yanagida, S., Stepped Light-Induced Transient Measurements of Photocurrent and Voltage in Dye Sensitized Solar Cells: Application for Highly Viscous Electrolyte Systems, Langmuir, 2005, 21, 10803-10807.

(34) Duffy, N. W.; Peter, L. M.; Rajapakse, R. M. G.; Wijayantha, K. G. U., A Novel Charge Extraction Method for the Study of Electron Transport and Interfacial Transfer in Dye Sensitised Nanocrystalline solar Cells, Electrochem. Comm., 2000, 2, 658-662.

(35) Wang, H.; Peter, L. M., A Comparison of Different Methods To Determine the Electron Diffusion Length in Dye-Sensitized Solar Cells, J. Phys. Chem. C, 2009, 113, 18125-18133.

(36) Furube, A.; Katoh, R.; Hara, K.; Sato, T.; Murata, S.; Arakawa, H.; Tachiya, M., Lithium

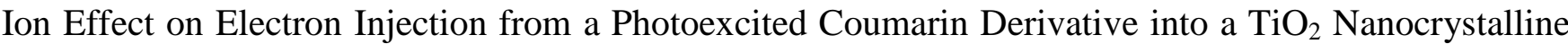
Film Investigated by Visible-to-IR Ultrafast Spectroscopy, J. Phys. Chem. B, 2005, 109, 16406-16414. 
Solar Cells and the Interpretation of the Diffusion Length, J. Phys. Chem. Lett., 2010, 1, 450-456.

(38) Jennings, J.R.; Li F.; Wang, Q., Reliable Determination of Electron Diffusion Length and Charge Separation Efficiency in Dye-Sensitized Solar Cells, J. Phys. Chem. C, 2010, 114, 14665-14674.

(39) Kambe, S.; Nakade, S.; Kitamura, T.; Wada, Y.; Yanagida, S., Influence of the Electrolytes on Electron Transport in Mesoporous $\mathrm{TiO}_{2}-$ Electrolyte Systems, J. Phys. Chem. B, 2002, 106, 2967-2972.

(40) Kopidakis, N.; Neale, N. R.; Frank, A. J., Effect of an Adsorbent on Recombination and Band-Edge Movement in Dye-Sensitized $\mathrm{TiO}_{2}$ Solar Cells: Evidence for Surface Passivation, J. Phys. Chem. B, 2006, 110, 12485-12489.

(41) Liu, Y.; Hagfeldt, A.; Xiao, X.-R.; Lindquist, S.-E., Investigation of Influence of Redox Species on the Interfacial Energetics of a Dye-Sensitized Nanoporous $\mathrm{TiO}_{2}$ Solar Cell, Sol. En. Mater. Sol. Cells, 1998, 55, 267-281.

(42) Kopidakis, N.; Benkstein, K.D.; van de Lagemaat, J.; Frank, A. J., Transport-Limited Recombination of Photocarriers in Dye-Sensitized Nanocrystalline $\mathrm{TiO}_{2}$ Solar Cells, J. Phys. Chem. B, 2003, 107, 11307-11315.

(43) Kopidakis, N.; Schiff, E. A.; Park, N.-G.; J. van de Lagemaat; Frank, A. J., Ambipolar Diffusion of Photocarriers in Electrolyte-Filled, Nanoporous TiO2, J. Phys. Chem. B, 2000, 104, 39303936.

(44) Miyashita, M.; Sunahara, K.; Nishikawa, T.; Uemura, Y.; Koumura, N.; Hara, K.; Mori, A.; Abe, T.; Suzuki, E.; Mori, S., Interfacial Electron-Transfer Kinetics in Metal-Free Organic DyeSensitized Solar Cells: Combined Effects of Molecular Structure of Dyes and Electrolytes, J. Am. Chem. Soc., 2008, 130, 17874-17881.

(45) Boschloo, G.; Häggman, L.; Hagfeldt, A., Quantification of the Effect of 4-tertButylpyridine Addition to $\mathrm{I}^{-} / \mathrm{I}_{3}{ }^{-}$Redox Electrolytes in Dye-Sensitized Nanostructured $\mathrm{TiO}_{2}$ Solar Cells, J. Phys. Chem. B, 2006, 110, 13144-13150. 
(46) Montanari, I.; Nelson, J.; Durrant, J. R., Iodide Electron Transfer Kinetics in DyeSensitized Nanocrystalline $\mathrm{TiO}_{2}$ Films, J. Phys. Chem. B, 2002, 106, 12203-12210.

(47) Fukui, A.; Komiya, R.; Yamanaka, R.; Islam, A.; Han, L., Effect of a Redox Electrolyte in Mixed Solvents on the Photovoltaic Performance of a Dye-Sensitized Solar Cell, Sol. En. Mater. Sol. Cells, 2006, 90, 649-658.

(48) Nazeeruddin, M. K.; Péchy, P.; Renouard, T.; Zakeeruddin, S. M.; Humphry-Baker, R.; Comte, P.; Liska, P.; Cevey, L.; Costa, E.; Shklover, V.; Spiccia, L.; Deacon, G. B.; Bignozzi, C. A.; Grätzel, M., Engineering of Efficient Panchromatic Sensitizers for Nanocrystalline $\mathrm{TiO}_{2}$-Based Solar Cells, J. Am. Chem. Soc., 2001, 123, 1613-1624.

(49) Wu, J.; Lan, Z.; Lin, J.; Huang, M.; Li, P., Effect of Solvents in Liquid Electrolyte on the Photovoltaic Performance of Dye-Sensitized Solar Cells, J. Power Source, 2007, 173, 585-591.

(50) Sunahara, K.; Ogawa, J.; Mori, S., A Method to Measure Electron Lifetime in DyeSensitized Solar Cells: Stepped Current Induced Measurement of Cell Voltage in the Dark, Electrochem. Comm., 2011, 13, 1420-1422. 
TABLE OF CONTENTS GRAPHIC:

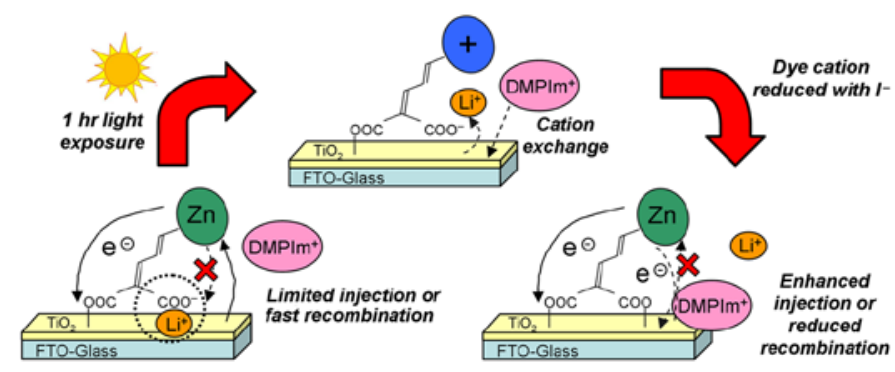

